\title{
Igf2 deletion alters mouse placenta endocrine capacity in a sexually dimorphic manner
}

\author{
Bethany R L Aykroyd, Simon J Tunster $\mathbb{( D}$ and Amanda N Sferruzzi-Perri \\ Centre for Trophoblast Research, Department of Physiology, Development and Neuroscience, University of Cambridge, Cambridge, UK
}

Correspondence should be addressed to A N Sferruzzi-Perri: ans48@cam.ac.uk

\begin{abstract}
The placenta regulates materno-fetal nutrient transfer and secretes hormones that enable maternal physiological support of the pregnancy. In mice, these functions are performed by the labyrinth (Lz) and junctional (Jz) zones, respectively. Insulin-like growth factor 2 (Igf2) is an imprinted gene expressed by the conceptus that is important for promoting fetal growth and placenta formation. However, the specific role of Igf2 in the $\mathrm{Jz}$ in regulating placental endocrine function and fetal development is unknown. This study used a novel model to investigate the effect of conditional loss of Igf2 in the $\mathrm{Jz}(\mathrm{Jz}-$ Igf2UE) on placental endocrine cell formation and the expression of hormones and IGF signaling components in placentas from female and male fetuses. Jz-Igf2UE altered gross placental structure and expression of key endocrine and signaling genes in a sexually dimorphic manner. The volumes of spongiotrophoblast and glycogen trophoblast in the Jz were decreased in placentas from female but not male fetuses. Expression of insulin receptor was increased and expression of the MAPK pathway genes (Mek1, P38 $\alpha$ ) decreased in the placental Jz of female but not male fetuses. In contrast, expression of the type-1 and -2 IGF receptors and the MAPK pathway genes ( $\mathrm{H}$-ras, $\mathrm{N}$-ras, $K$-ras) was decreased in the placental Jz from male but not female fetuses. Expression of the steroidogenic gene, Cyp17a1, was increased and placental lactogen-2 was decreased in the placenta of both sexes. In summary, we report that Jz-Igf2UE alters the cellular composition, IGF signaling components and hormone expression of the placental Jz in a manner largely dependent on fetal sex.
\end{abstract}

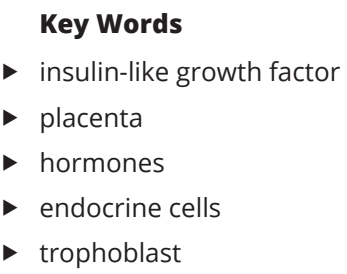

Key Words

$\rightarrow$ insulin-like growth factor

placenta

- endocrine cells

- trophoblast

\section{Introduction}

Pregnancy success depends upon the appropriate allocation of nutrients between the fetus for growth and development and the mother to sustain the pregnancy and subsequent lactation. Failure to achieve this maternofetal nutrient balance can lead to pregnancy complications including abnormal birth weight and gestational diabetes (Sferruzzi-Perri et al. 2013a, 2020, Plows et al. 2018). Inappropriate nutrient allocation during gestation can also program offspring for life-long health complications including metabolic and cardiovascular dysfunction
(Fowden et al. 2006, Gluckman et al. 2008, Camm et al. 2018). The placenta is a main determinant of materno-fetal nutrient allocation. It controls nutrient transport between the mother and fetus and secretes hormones which adapt maternal physiology to support fetal nutrient supply and growth (Sferruzzi-Perri \& Camm 2016, Napso et al. 2018). Previous work has largely focused on understanding the importance of placental transport function in the context of pregnancy outcome (Fowden et al. 2006, Desforges \& Sibley 2009, Dimasuay et al. 2016, Gaccioli \& Lager 2016). 
However, much less is known about the role and regulation of placental endocrine function in pregnancy.

Information on the role of placental hormones has principally been derived from association studies between maternal serum hormone levels or placental hormone gene expression and fetal growth in humans (Mirlesse et al. 1993, McIntyre et al. 2000, Chellakooty et al. 2004, Koutsaki et al. 2011), as well as studies administering or genetically manipulating the expression of placental hormones and their receptors in experimental animals or cultured cells (Nogues et al. 1997, Carter 2012, Burton et al. 2016, Napso et al. 2018, Sferruzzi-Perri et al. 2020). Placental hormones, such as growth hormone variant and members of the placental lactogen/prolactin gene family reduce whole body insulin sensitivity of the mother by altering the expression of insulin signaling components in the skeletal muscle and white adipose tissue (Jarrett et al. 1984, Barbour et al. 2002, 2004). Similarly, progesterone induces insulin resistance in the liver, skeletal muscle and adipose tissue by inhibiting the phosphoinositide 3-kinase (PI3K) signaling pathway (Sutter-Dub \& Dazey 1979, Leturque et al. 1984, Wada et al. 2010). In contrast, estrogen increases maternal insulin sensitivity as loss of aromatase (Сур19), a key rate-limiting gene for estrogen production, leads to glucose intolerance and decreased insulin sensitivity (Takeda et al. 2003). Prolactins and placental lactogens also increase the number, size and insulin secretion of beta cells in the pancreas to balance the level of insulin resistance in the mother during pregnancy (Vasavada et al. 2000, Brelje et al. 2004, Weinhaus et al. 2007).

In addition to mediating systemic physiological adaptations in the mother during pregnancy, placental hormones act locally to promote angiogenesis and immunomodulation that are important for fetal development. Pregnancy-specific glycoproteins (PSGs) are synthesised by the placenta and induce the secretion of anti-inflammatory cytokines by maternal leukocytes to promote a tolerogenic decidual environment (Snyder et al. 2001). They also promote endothelial tube formation and the expression of angiogenic growth factors (Blois et al. 2012).

The mouse is a useful species for studying placental endocrine function. In mice, the endocrine and transport functions of the placenta are carried out in the structurally discrete junctional zone (Jz) and labyrinth zone (Lz), respectively (Coan et al. 2006). This differs to humans, where both functions are performed by the placental syncytiotrophoblast (Dearden \& Ockleford 1983), preventing evaluation of their importance in isolation. In mice, the placental Jz forms under genetic instruction distinct from the Lz (Simmons \& Cross 2005) and the two zones can be physically separated (Sferruzzi-Perri et al. 2009). The Jz is composed of three major endocrine cell types: spongiotrophoblasts (SpT), glycogen cells (GC) and trophoblast giant cells (TGC). Murine GC are considered to be analogous to the human placental extravillous cytotrophoblast, which also accumulate glycogen (Wislocki \& Bennett 1943, Georgiades et al. 2002). SpT, GC and TGC vary in the repertoire of hormones they express (McLellan et al. 2005, Simmons et al. 2008, LaVoie \& King 2009) and within the mouse placenta, they are the only cells that express the gene; trophoblast-specific protein alpha (Tpbpa) (Lescisin et al. 1988). While there are some differences in the hormones expressed in mouse and human placenta, many mouse-specific hormone genes are structurally similar to those in human and perform similar functions (Soares 2004, Carter 2012). Moreover, many genes, proteins and cellular pathways governing placental formation and function overlap in mice and humans (Cox et al. 2009, 2011).

Insulin-like growth factor 2 (Igf2) is a paternally expressed imprinted gene that is highly expressed in the fetus and placenta of mice and humans (DeChiara et al. 1991, Sferruzzi-Perri et al. 2011a). In the human placenta, IGF2 is highly expressed by the villous and extravillous cytotrophoblasts during the first trimester and the extravillous cytotrophoblasts during the third trimester (Brice et al. 1989, Han et al. 1996, Thomsen et al. 1997). In mice, $I g f 2$ is expressed by the placental trophoblast and fetal vasculature from D9.5 (Redline et al. 1993). Within the $\mathrm{Jz}$ I If 2 expression is initially strongest in the SpT but from $\sim \mathrm{D} 12.5$, Igf2 is restricted to the GC (Redline et al. 1993). IGF2 is a small $7.5 \mathrm{kDa}$ protein that promotes mitogenesis, metabolism, differentiation and survival of multiple cell types (Jones \& Clemmons 1995, Curchoe et al. 2005, Guvakova 2007). Its anabolic actions are mostly mediated via binding to the type-1 IGF receptor (IGF1R) or insulin receptor (INSR), which typically leads to activation of the PI3K-AKT or RAS-MAPK-ERK pathways (McClain 1991, Forbes et al. 2008, Kent et al. 2012, Sferruzzi-Perri et al. 2017, Sferruzzi-Perri 2018). However, IGF2 can also bind to the type-2 IGF receptor (IGF2R), which can result in its degradation (Oka et al. 1985, McClain 1991, SferruzziPerri et al. 2017, Sferruzzi-Perri 2018).

IGF2 is an important growth regulator that has been implicated in the development of human fetal growth disorders, namely Silver-Russell syndrome (SRS) https://joe.bioscientifica.com https://doi.org/10.1530/JOE-20-0128 (c) 2020 Society for Endocrinology Published by Bioscientifica Ltd. Printed in Great Britain 
and Beckwith-Wiedemann syndrome (BWS), which are characterised by fetal growth restriction and fetal overgrowth, respectively. Aberrant methylation of the IGF2 imprinting control region (ICR1) has been implicated in both conditions, with hypomethylation of ICR1 reported in 37-63\% of SRS cases and hypermethylation of ICR1 reported in up to 10\% of BWS cases (reviewed in Õunap 2016). Moreover, expression of IGF2 in human chorionic villus samples at week 11-13 of gestation has been positively correlated with birth weight (Demetriou et al. 2014) and exogenous IGF2 induced proliferation of primary human trophoblast in vitro (Chen et al. 2016). In mice, constitutive deletion of $I g f 2$ results in feto-placental growth restriction (DeChiara et al. 1991) in association with reduced Jz formation, GC abundance and glycogen content (Lopez et al. 1996). In addition, wild-type mouse dams carrying litters that lack the placental Lz-specific Igf2 isoform (Igf2PO) have altered body weight and increased circulating insulin, corticosterone and glucose concentrations when fed ad libitum and/or undernourished during pregnancy (Sferruzzi-Perri et al. 2011b). Finally, Igf2 and PI3K are correlated with the expression of placental hormone genes in the mouse placenta (Ishida et al. 2007, Sferruzzi-Perri et al. 2016). Together, these findings suggest that $I g f 2$ may play a role in regulating placental endocrine function and consequently maternal metabolic state, but the mechanism through which this is achieved is unclear. However, to date our understanding has been limited to global or Lz specific manipulations of $I g f 2$ in mice.

In this study, we generated a novel mouse model in which $I g f 2$ is specifically knocked-out in the placental Jz (Jz-Igf2UE) using the TpbpaCre line, which is exclusively expressed in Jz cells (Simmons et al. 2007). This enabled us to explore the role of Jz-derived Igf2 on the endocrine phenotype of the mouse placenta, including cellular composition of the $\mathrm{Jz}$ and hormone expression. As the placenta has been shown to exhibit sexually dimorphic responses to environmental and genetic manipulations (Rosenfeld 2015, Kalisch-Smith et al. 2017, Barke et al. 2019, Napso et al. 2019), analyses were conducted separately for males and females fetuses.

\section{Materials and methods}

\section{Animal housing and time mating}

The University of Cambridge Animal Welfare and Ethical Review Body approved all experiments carried out under the UK Home Office Animals (Scientific Procedures) Act
1986. Homozygous TpbpaCre females (Simmons et al. 2007) (8-10 weeks) were time-mated with heterozygous Igf2Flox males (Haley et al. 2012) to generate litters with control and Jz-Igf2UE fetuses. Both strains were on a C57BL/6NCrl (Charles River) background for $>10$ generations. Mice were housed under standard $12 \mathrm{~h}$ light:12 h darkness photocycle with $21 \%$ oxygen at $22^{\circ} \mathrm{C}$ and ad libitum access to water and standard chow diet (Rat and Mouse No.3; Special Dietary Services, Witham, UK).

\section{Tissue collection}

Copulatory plug detection was defined as pregnancy day (D)1. On D16 of gestation, dams were killed by cervical dislocation. D16 was selected for analysis as the placental Jz is at its maximal size (Coan et al. 2006) and mouse dams are most insulin resistant and glucose intolerant compared to non-pregnant state (Musial et al. 2016). Fetuses and placentas were weighed. Fetal tails were collected to determine Igf2Flox genotype (FPrimer 5'-TTACAGTTCAAAGCCACCACG-3', RPrimer: 5'-GCCAAAGAGATGAGAAGCACC-3') and sex by Sry genotyping (FPrimer: 5'-GTGGGTTCCTGTCCCACTGC-3', RPrimer: 5'-GGCCATGTCAAGCGCCCCAT-3' using FPrimer: 5'-TGGTTGGCATTTTATCCCTAGAAC-3', RPrimer: 5'-GCAACATGGCAACTGGAAACA-3' as a PCR autosomal gene control) using PCR and agarose gel electrophoresis. Placentas were bisected and one half was separated into $\mathrm{Jz}$ and $\mathrm{Lz}$ and snap frozen for gene expression analysis. The other half was either fixed in $4 \%$ paraformaldehyde for histological assessment or frozen for glycogen concentration analysis. The placentas chosen for analysis from each group were selected on the basis of being the closest to the mean placental weight of each litter.

\section{Histological analysis}

Fixed placentas were paraffin embedded, sectioned exhaustively at $8 \mu \mathrm{m}$ with the first 20 midline placental sections kept for analysis and then every 20th section stained with hematoxylin and eosin ( $n=8 /$ sex/genotype, from 8 litters). The placental mid-line was determined by the presence of all three placental layers (decidua basalis (Db), Jz and Lz) and a complete chorion in the section. Images were captured using a NanoZoomer 2.0-RS (Hamamatsu, Hamamatsu City, Japan) and gross placental structure analysed using the newCAST System (Visiopharm, Hørsholm, Denmark). The proportion https://joe.bioscientifica.com https://doi.org/10.1530/JOE-20-0128 (c) 2020 Society for Endocrinology Published by Bioscientifica Ltd. 
of $\mathrm{Db}, \mathrm{Jz}$ and $\mathrm{Lz}$ in each section was determined using point counting and values were multiplied by placental weight to provide an estimated volume of each region (Coan et al. 2004). The first complete mid-line placental section was used to quantify the proportion of different Jz and Db cells. These comprised SpT, GC, TGC, decidual stromal cells (Db_S), decidual glycogen cells (Db_GC) and decidual vessels (Db_V). When multiplied by the corresponding Jz or Db volume, this provided estimated volumes of each cell type within the Jz and $\mathrm{Db}$. The size of 100 individual Jz glycogen cells was measured in a midline placental section, using NDP.view2 viewing software (Hamamatsu).

\section{Periodic acid-Schiff (PAS) stain}

Sections ( $n=2 /$ sex/genotype, across 8 litters) were stained with PAS to visualise placental glycogen accumulation. Sections were dewaxed, rehydrated and incubated in $0.5 \%$ periodic acid (Thermo Fisher Scientific) for $5 \mathrm{~min}$, rinsed with distilled water, stained with Schiff's reagent (SigmaAldrich) for $15 \mathrm{~min}$ and rinsed in distilled water. Slides were counterstained with hematoxylin, dehydrated and mounted.

\section{In situ hybridisation}

In situ hybridisation was used to assess the spatial expression of $I g f 2$, Prl8a8 and Tpbpa genes. Tpbpa probe generation has been previously described (Lescisin et al. 1988). Novel probes for Prlsa8 and $I g f 2$ were generated by PCR amplification of a 512bp region of Prl8a 8 (primer sequences: 5'-CGGCGGGATGAGATTGTTTT-3', 5'-GCAATGAACTTTTGTGGAGCG-3') and a 507bp region of Igf2 (primer sequences: 5'-CTCATCTCTTTGGCC TTCGC-3', 5'-TCACTGATGGTTGCTGGACA-3') from placental cDNA and cloning into the pDrive vector system (Qiagen). Digoxigenin labeled riboprobes were generated from linearised plasmid template using the DIG RNA Labelling mix (Roche).

In situ hybridization was performed with probe hybridisation at $60^{\circ} \mathrm{C}$ overnight, as previously described (Rakoczy et al. 2017). BM-Purple alkaline phosphatase substrate aided staining development and Nuclear Fast Red (Sigma-Aldrich) was used to counterstain sections before mounting. Images for sense probes of $I g f 2$ and Tpbpa are shown in Supplementary Fig. 1A and B (see section on supplementary materials given at the end of this article). The integrity of the Jz boundaries to the $\mathrm{Db}$ and $\mathrm{Lz}(\mathrm{Db} / \mathrm{Jz}$ and $\mathrm{Jz} / \mathrm{Lz}$ boundaries) was qualitatively assessed using sections stained for Tpbpa and Prl8a8 by in situ hybridisation ( $n=4$ per sex/genotype). The amount of $\mathrm{Jz}$ interdigitation into the $\mathrm{Lz}$ was also qualitatively assessed by ranking samples from least to most interdigitated.

\section{Immunohistochemistry}

Placenta sections were dewaxed and rehydrated. Antigen retrieval with sodium citrate buffer $(0.01 \mathrm{M}$ sodium citrate, $0.05 \%$ Tween 20, pH 6) was performed at $80^{\circ} \mathrm{C}$ for $1 \mathrm{~h}$. Sections were blocked (10\% goat serum, $1 \%$ BSA in PBS) for $1 \mathrm{~h}$ at room temperature before incubation with anticaspase 3 (Cell Signalling, Cleaved Caspase-3 (Asp175) 9661; $1: 200$ dilution in $1 \%$ BSA/PBS) overnight at $4^{\circ} \mathrm{C}$. Sections were incubated with goat-anti-rabbit secondary antibody (Abcam, ab6720; 1:1000 dilution in 1\% BSA/PBS) for $1 \mathrm{~h}$ at room temperature and streptavidin-horseradish peroxidase (Rockland, Limerick, PA, USA, S000-03, 1:250 dilution in PBS) for $1 \mathrm{~h}$ at room temperature. Sections were stained with 3,3'-Diaminobenzidine (Abcam) for $5 \mathrm{~min}$ and counterstained with hematoxylin before dehydrating and mounting. The number of caspase positive cells within the $\mathrm{Db}$ and $\mathrm{Jz}$ of scanned slides was counted in each section.

\section{Placental gene expression}

RNA was extracted from separated placental zones ( $n \geq 8$ /sex/genotype, from 8 litters) using the RNeasy Plus Mini Kit (Qiagen) and reverse transcribed using the High Capacity cDNA RT Kit minus RT inhibitor (Applied Biosystems) following manufacturer's instructions. Samples were analysed in duplicate using MESA Blue SYBR (Eurogentec, Seraing, Belgium) and primers synthesised by Sigma-Aldrich on a 7500 fast real-time PCR machine (Applied Biosystems). Cycling conditions were as follows: $3 \mathrm{~min}$ at $95^{\circ} \mathrm{C}$ then 40 cycles of: $30 \mathrm{~s}$ at $95^{\circ} \mathrm{C}, 30 \mathrm{~s}$ at $57^{\circ} \mathrm{C}$ and $90 \mathrm{~s}$ at $72^{\circ} \mathrm{C}$. Primer sequences were designed or sourced from published papers (Supplementary Table 1). Primers were verified to have an efficiency $>80 \%$ and yield a PCR product of the correct size and sequence. The expression of each gene of interest was normalized to the geometric mean expression of the reference genes Hprt and Ywhaz, which were unaffected by sex or genotype. https://joe.bioscientifica.com https://doi.org/10.1530/JOE-20-0128 (c) 2020 Society for Endocrinology Published by Bioscientifica Ltd. Printed in Great Britain 


\section{Glycogen assay}

Placental glycogen content was indirectly measured ( $n \geq 7$ /sex/genotype, across $n \geq 7$ litters), using amyloglucosidase as described (Sferruzzi-Perri et al. 2013b).

\section{Statistics}

As part of our initial quality control check, a Grubb's test was performed as standard on all datasets to identify any outliers (using the Prism Grubbs' test, GraphPad Software Inc.), which were removed prior to statistical analysis. For the vast majority of our analyses no outliers were identified and thus analyses were conducted using the complete sample set. Where the Grubb's test indicated an outlier, this generally resulted in the exclusion of a single sample from one group. The details of final sample numbers per group are stated in the figure/table legends. Since our primary research question was to determine the effect of genotype, we used $t$-tests to determine significant differences between Jz-Igf2UE and control groups within one sex. By performing separate analyses for males and females, we are able to control for the potential effect of sex. Statistical analyses were performed using Prism (GraphPad Software Inc.) and considered statistically significant when $P<0.05$.
Results are expressed as mean + /- S.E.M., with $n=$ number of placentas or fetuses presented per group.

\section{Results}

\section{Confirmation that Igf2 has been successfully reduced in the placental Jz}

We first sought to confirm that our genetic approach resulted in the specific reduction of $I g f 2$ in the placental $\mathrm{Jz}$. The Igf2 gene is expressed by the developing conceptus from the 2-cell stage (Stojanov et al. 1999) and the Tpbpa gene is expressed from $D 7$ (Lescisin et al. 1988). Thus, TpbpaCre mediated loss of Igf 2 would be predicted to affect all Jz cell types from shortly after implantation at D5. Using qPCR on separated placental zones on D16 of pregnancy, we found that while Igf2 expression was unaltered in the Lz, Igf2 expression was reduced in the Jz of Jz-Igf2UE placentas of both female and male fetuses by $50 \%$ and $45 \%$, respectively (Fig. $1 \mathrm{~A}$ and B). Consistent with previous reports (Coan et al. 2006, Redline et al. 1993), in situ hybridisation demonstrated widespread expression of $I g f 2$ in the $\mathrm{Lz}$ and GC of control placentas, with low expression detected in the SpT and TGC (Fig. $1 \mathrm{C}$ and D). Expression of $\mathrm{Ig} 2 \mathrm{2}$ was maintained in the Lz of
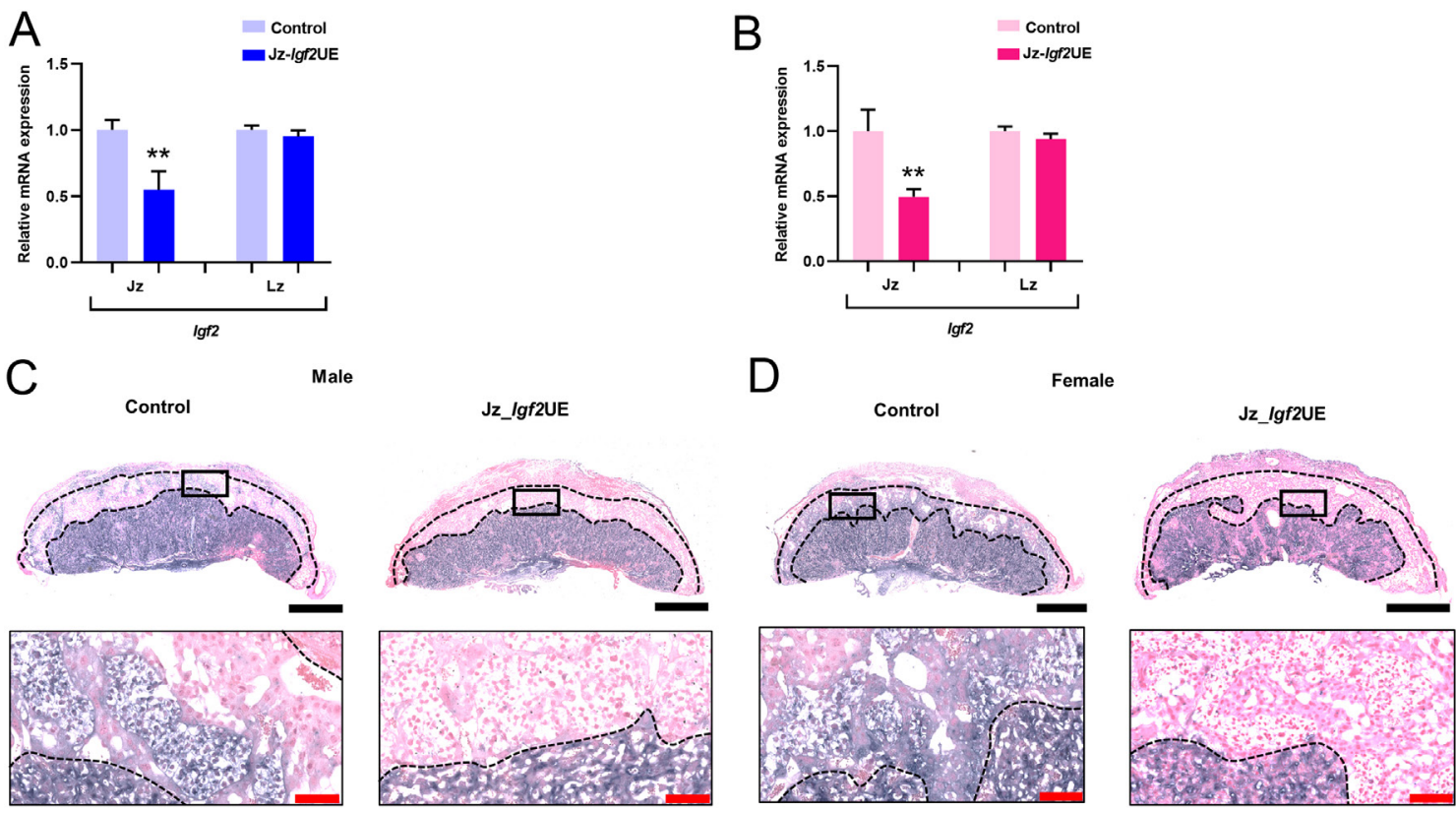

Figure 1

Igf2 expression is significantly reduced in the Jz by qPCR and completely abolished in the Jz by in situ hybridisation in D16 mouse placentas with Jz-Igf2UE. (A and B) Expression of Igf2 in isolated Jz and Lz samples relative to housekeeping geometric mean of Hprt and Ywhaz using qPCR in (A) males (control $n=10$ and $\mathrm{UE} n=8$ ) and (B) females (control $n=10$ and UE $n=12$ ) across 8 litters. Values presented as mean + S.E.M. with significance assessed by $t$-test $(P<0.01=* *)$. (C and D) In situ hybridization of Igf2 in (C) males and (D) females. Black boxes represent the area magnified in the image. Black bar represents $1 \mathrm{~mm}$. Red bar represents $100 \mu \mathrm{m}$. 
Table 1 The effect of Jz-lgf2UE on conceptus weight, placental volume and the proportion of cell types within the Jz and Db of D16 mouse placentas in males.

\begin{tabular}{|c|c|c|}
\hline & \multicolumn{2}{|c|}{ Male } \\
\hline & Control & $\mathrm{Jz}-\lg 2 \mathrm{UE}$ \\
\hline Fetal weight (mg) & $409.0 \pm 10.0$ & $409.4 \pm 10.2$ \\
\hline Placental weight (mg) & $114.4 \pm 2.8$ & $114.0 \pm 2.3$ \\
\hline Db volume $\left(\mathrm{mm}^{3}\right)$ & $17.0 \pm 0.9$ & $15.5 \pm 0.9$ \\
\hline Jz volume $\left(\mathrm{mm}^{3}\right)$ & $45.1 \pm 3.0$ & $44.5 \pm 2.7$ \\
\hline Lz volume $\left(\mathrm{mm}^{3}\right)$ & $49.7 \pm 1.0$ & $50.5 \pm 1.9$ \\
\hline Jz_SpT volume $\left(\mathrm{mm}^{3}\right)$ & $27.7 \pm 1.8$ & $26.4 \pm 2.0$ \\
\hline Jz_GC volume $\left(\mathrm{mm}^{3}\right)$ & $15.6 \pm 1.5$ & $15.0 \pm 1.5$ \\
\hline Jz_TGC volume $\left(\mathrm{mm}^{3}\right)$ & $2.3 \pm 0.3$ & $3.2 \pm 0.5$ \\
\hline $\mathrm{Db} \mathrm{S}$ volume $\left(\mathrm{mm}^{3}\right)$ & $10.7 \pm 0.8$ & $9.6 \pm 0.8$ \\
\hline $\mathrm{Db}$ GC volume $\left(\mathrm{mm}^{3}\right)$ & $5.8 \pm 0.6$ & $5.1 \pm 0.4$ \\
\hline $\mathrm{Db} \vee \mathrm{V}$ volume $\left(\mathrm{mm}^{3}\right)$ & $0.9 \pm 0.3$ & $0.8 \pm 0.2$ \\
\hline Jz_GC/Jz_SpT & $0.57 \pm 0.05$ & $0.60 \pm 0.08$ \\
\hline $\mathrm{Db}$ GC/Jz_GC & $0.39 \pm 0.05$ & $0.38 \pm 0.06$ \\
\hline Db_GC/(Jz_GC + Db_GC) & $0.28 \pm 0.02$ & $0.27 \pm 0.03$ \\
\hline Average Jz_GC cell size $\left(\mu \mathrm{m}^{2}\right)$ & $158.0 \pm 11.0$ & $149.3 \pm 7.9$ \\
\hline
\end{tabular}

Weight data displayed for males: Control $n=22$ and Jz-Igf2UE $n=30$, across 14 litters, Control:Jz-Igf2UE $=42: 58$. Volume data: $n=8$ per genotype, across 8 litters. Values presented as mean \pm s.E.M. with significance assessed by $t$-test.

Db, Decidua; Db_GC, Db glycogen cell; Db_S, Db stroma; Db_V, Db vessel; $\mathrm{Jz}$, Junctional zone; Jz_GC, Jz glycogen cells; Jz_SpT, Jz spongiotrophoblasts; Jz_TGC, Jz trophoblast giant cell; Lz, Labyrinth zone.

Table 2 The effect of Jz-lgf2UE on conceptus weight, placental volume and the proportion of cell types within the Jz and Db of D16 mouse placentas in females.

\begin{tabular}{|c|c|c|}
\hline & \multicolumn{2}{|c|}{ Female } \\
\hline & Control & Jz-lgf2UE \\
\hline Fetal weight (mg) & $386.4 \pm 10.2$ & $395.7 \pm 7.1$ \\
\hline Placental weight (mg) & $112.0 \pm 3.4$ & $108.4 \pm 3.1$ \\
\hline Db volume $\left(\mathrm{mm}^{3}\right)$ & $18.7 \pm 1.4$ & $18.8 \pm 1.9$ \\
\hline Jz volume $\left(\mathrm{mm}^{3}\right)$ & $48.3 \pm 2.2$ & $41.7 \pm 1.4^{a}$ \\
\hline Lz volume $\left(\mathrm{mm}^{3}\right)$ & $56.5 \pm 3.0$ & $53.2 \pm 3.2$ \\
\hline Jz_SpT volume $\left(\mathrm{mm}^{3}\right)$ & $30.1 \pm 1.5$ & $25.9 \pm 0.8^{a}$ \\
\hline Jz_GC volume $\left(\mathrm{mm}^{3}\right)$ & $14.8 \pm 0.8$ & $12.5 \pm 0.5^{a}$ \\
\hline Jz_TGC volume $\left(\mathrm{mm}^{3}\right)$ & $2.9 \pm 0.5$ & $2.3 \pm 0.3$ \\
\hline Db_S volume $\left(\mathrm{mm}^{3}\right)$ & $12.9 \pm 1.2$ & $11.7 \pm 1.3$ \\
\hline Db_GC volume $\left(\mathrm{mm}^{3}\right)$ & $4.8 \pm 0.3$ & $6.1 \pm 0.6$ \\
\hline $\mathrm{Db} \vee \mathrm{V}$ volume $\left(\mathrm{mm}^{3}\right)$ & $0.9 \pm 0.2$ & $1.1 \pm 0.2$ \\
\hline Jz_GC_Jz_SpT & $0.49 \pm 0.02$ & $0.49 \pm 0.03$ \\
\hline $\mathrm{Db} \_\mathrm{GC} / \mathrm{Jz}$ _GC & $0.33 \pm 0.03$ & $0.47 \pm 0.06 \mathrm{a}$ \\
\hline Db_GC/(Jz_GC + Db_GC) & $0.24 \pm 0.01$ & $0.31 \pm 0.03^{a}$ \\
\hline Average Jz_GC cell size $\left(\mu \mathrm{m}^{2}\right)$ & $142.0 \pm 2.7$ & $149.3 \pm 7.9$ \\
\hline
\end{tabular}

Weight data displayed for females: Control $n=23$ and Jz-Igf2UE $n=29$, across 14 litters, Control:Jz-Igf2UE $=44: 56$. Volume data: $n=8$ per genotype, across 8 litters. Values presented as mean \pm s.E.M. with significance assessed by $t$-test $(P<0.05=a)$.

Db, Decidua; Db_GC, Db glycogen cell; Db_S, Db stroma; Db_V, Db vessel; Jz, Junctional zone; Jz_GC, Jz glycogen cells; Jz_SpT, Jz spongiotrophoblasts; Jz_TGC, Jz trophoblast giant cell; Lz, Labyrinth zone.

(C) 2020 Society for Endocrinology Published by Bioscientifica Ltd. Printed in Great Britain
Jz-Igf2UE placentas, but $I g f 2$ could not be detected in the Jz of mutants of either sex (Fig. 1C and D). Thus, we were able to successfully ablate Igf2 expression in the Jz.

\section{$\mathrm{Jz}$ Igf2 loss affects placental Jz structure but not fetal growth}

Jz-Igf2UE did not affect fetal or placental weight of male or female conceptuses on D16 (Tables 1 and 2). Using stereology, gross placental structure and abundance of cell types in the Jz and Db were unaffected by Jz-Igf2UE in male fetuses (Table 1). However, Jz volume and the constituent volumes of SpT and GC in females was significantly decreased in response to Jz-Igf2UE (Table 2). There was no effect of Jz-Igf2UE on $\mathrm{Lz}$ or Db volume or abundance of $\mathrm{Db}$ cell types in the placentas of female fetuses (Table 2). Thus, Jz-Igf2UE affects the formation of the placental Jz in female, but not male placentas.

\section{Jz Igf2 loss does not affect Jz cell marker expression, glycogen storage or apoptosis levels}

There were no significant changes in placental glycogen concentration or Jz GC size between control and Jz-Igf2UE placentas for either sex (Fig. 2A, B, C and D). Moreover, glycogen localisation using PAS staining to the placental $\mathrm{Jz}$ and Db GCs was not visibly different between control and Jz-Igf2UE placentas (Fig. 2E and F).

Expression of the $\mathrm{Jz}$ lineage markers, Prl8a8 for SpT, Gjb3 for GC and Hand1 for TGC were measured in the Jz by qPCR to assess if they may be affected by Jz-Igf2UE (Fig. 3A and B). While there was no significant effect of Jz-Igf2UE on the expression of Prl8a8 or Hand1 in either sex $G j b 3$ expression trended to be reduced in the placental Jz of male, but not female fetuses (Fig. 3A and $\mathrm{B}$ ).

We next used in situ hybridisation for the Jz marker Tpbpa and the SpT marker Prl8a8 to visually assess the integrity of the $\mathrm{Db} / \mathrm{Jz}$ and $\mathrm{Jz} / \mathrm{Lz}$ boundaries (Fig. 3C and D). The placental region boundaries appeared intact and there was no visual difference in Tpbpa or Prl8a8 staining in response to Jz-Igf2UE, regardless of fetal sex. However, qualitatively, Jz interdigitation was less in females, but not males with Jz-Igf2UE compared to control (although females controls had more interdigitation than male controls). There was no difference in the levels of apoptosis in the Jz or Db of either males or females with Jz-Igf2UE as indicated by cleaved caspase-3 (Supplementary Figs 1C and 2). Thus, despite sexually disparate effects on Jz formation, Jz-Igf2UE does not alter the expression of endocrine cell 

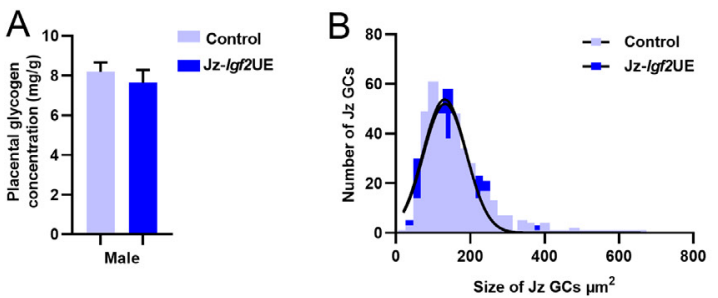

E

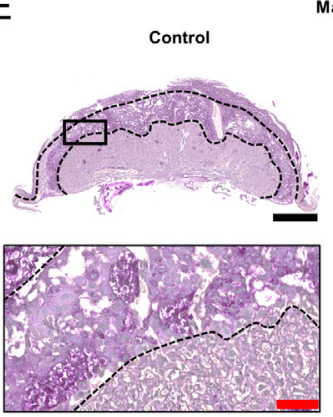

Male
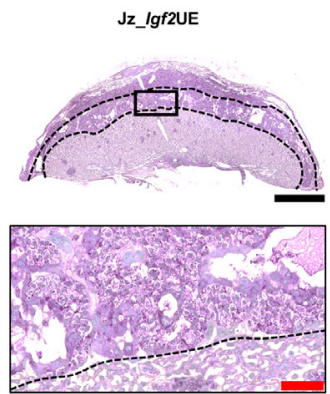
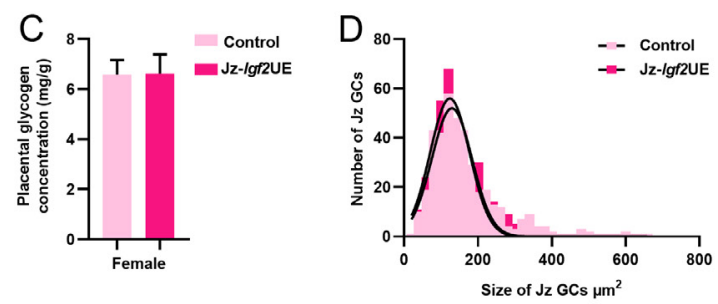

F

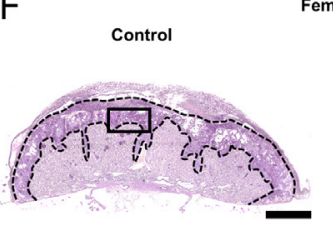

Female
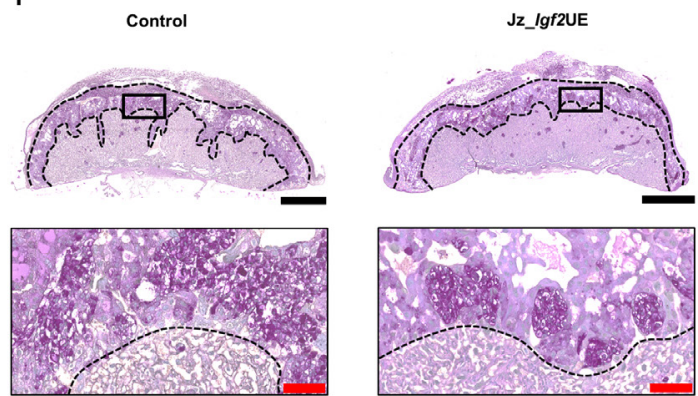

\section{Figure 2}

Jz-Igf2UE does not alter placental glycogen concentration or Jz GC size at D16 of mouse pregnancy. (A and C) Placental glycogen concentration in (A) males and (C) females with Jz-lgf2UE. $n=7-8$ per sex and genotype, across 8 litters. (B and D) Size of Jz glycogen cells in (B) males and (D) females. $n=4$ per sex and genotype, across 4 litters. ( $E$ and F) Pas stain of glycogen containing cells in (E) males and (F) females. Black boxes represent the area magnified in the image. Black bar represents $1 \mathrm{~mm}$. Red bar represents $100 \mu \mathrm{m}$.

lineage marker genes, glycogen accumulation or apoptosis levels in placentas of either sex.

\section{Jz Igf2 loss affects the expression of the IGF2 signaling pathway in the placental Jz}

To explore whether the fetal sex-dependent effects of Jz-Igf2UE on Jz morphology may be related to changes in the expression of signaling components downstream of IGF2, we quantified the mRNA expression of IGF2 receptors, Igf1r, Igf2r and Insr, as well as PI3K-AKT (P85, $P 110 \alpha, P 110 \beta, A k t$ and Gsk3) and RAS-MAPK-ERK (H-ras, $\mathrm{N}$-ras, K-ras, Mek1, Mek2, Erk1, Erk2 and P38a) pathway genes in the placental Jz (Fig. 4). In the placenta of male fetuses, Jz-Igf2UE significantly reduced the expression of $I g f 1 r$ by $45 \%$ and $I g f 2 r$ by $16 \%$ in the Jz but had no effect on Insr (Fig. 4A). Conversely, Jz-Igf2UE increased Insr expression by $43 \%$ in the placental $\mathrm{Jz}$ of females without an effect on $I g f 1 r$ or $I g f 2 r$ (Fig. 4B). The expression of $p 110 \beta$ trended to be increased in females with Jz-Igf2UE, although, overall, there were no significant changes in the expression of PI3K-AKT pathway genes with Jz-Igf2UE in either fetal sex (Fig. 4C and D). However, there were sex-specific alterations to genes in the RAS-MAPK-ERK pathway with Jz-Igf2UE. Males with Jz-Igf2UE had significant decreases in the expression of $\mathrm{H}$-ras (23\%), $\mathrm{N}$-ras (25\%) and $\mathrm{K}$-ras (30\%) and showed trends for a decrease in Mek1 and Mek2 (Fig. 4E). In females, Jz-Igf2UE significantly reduced the expression of Mek1 by $16 \%$ and P38 $\alpha$ by $18 \%$ (Fig. 4F). Taken together, Jz-Igf 2 UE affects the expression of IGF2 signaling components by the placental Jz in a manner dependent on fetal sex.

\section{Jz Igf2 loss affects the expression of hormones by the placental Jz}

To examine whether Jz-Igf2UE affects the placental capacity to produce hormones, we quantified the expression of selected Prl (Prl3b1 and Prl3d1), Psg (Psg21 and Psg23) and steroidogenic synthetic pathway genes (Hmgcr, Stard1, Cyp11a1, 3bhsd and Cyp17a1) by qPCR (Fig. 5). In response to Jz-Igf2UE, the expression of Cyp17a1 was significantly increased in the placental Jz of both males and females by $49 \%$ and 63\%, respectively (Fig. $5 \mathrm{~A}$ and B). Moreover, Prl3b1 was significantly decreased in the placental $\mathrm{Jz}$ by $19 \%$ and $25 \%$ in females and males with Jz-Igf2UE, respectively (Fig. 5C and D). However, males, but not females, with Jz-Igf2UE also had reduced expression of $\mathrm{Hmgcr}$ and Stard1 with values 23\% and 29\% lower than controls, respectively (Fig. 5A and B). There were non-significant trends for increased expression of Psg21 in the placental Jz of female fetuses and decreased expression of Prl2c2 in males with Jz-Igf2UE. Jz expression of Cyp11a1, 3bhsd, Prl3d1 and Psg23 was not affected by 
B

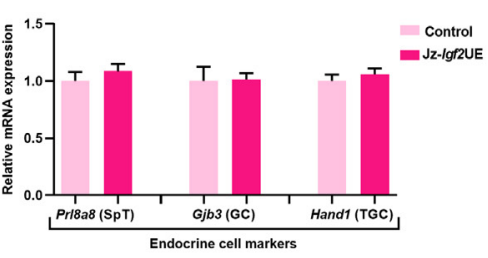

C

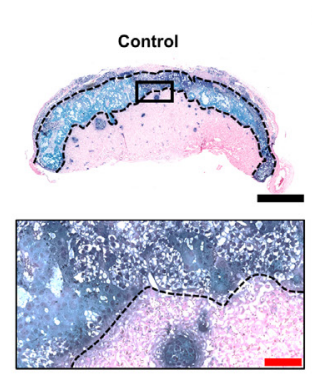

Male

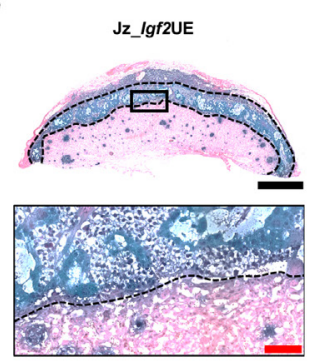

D
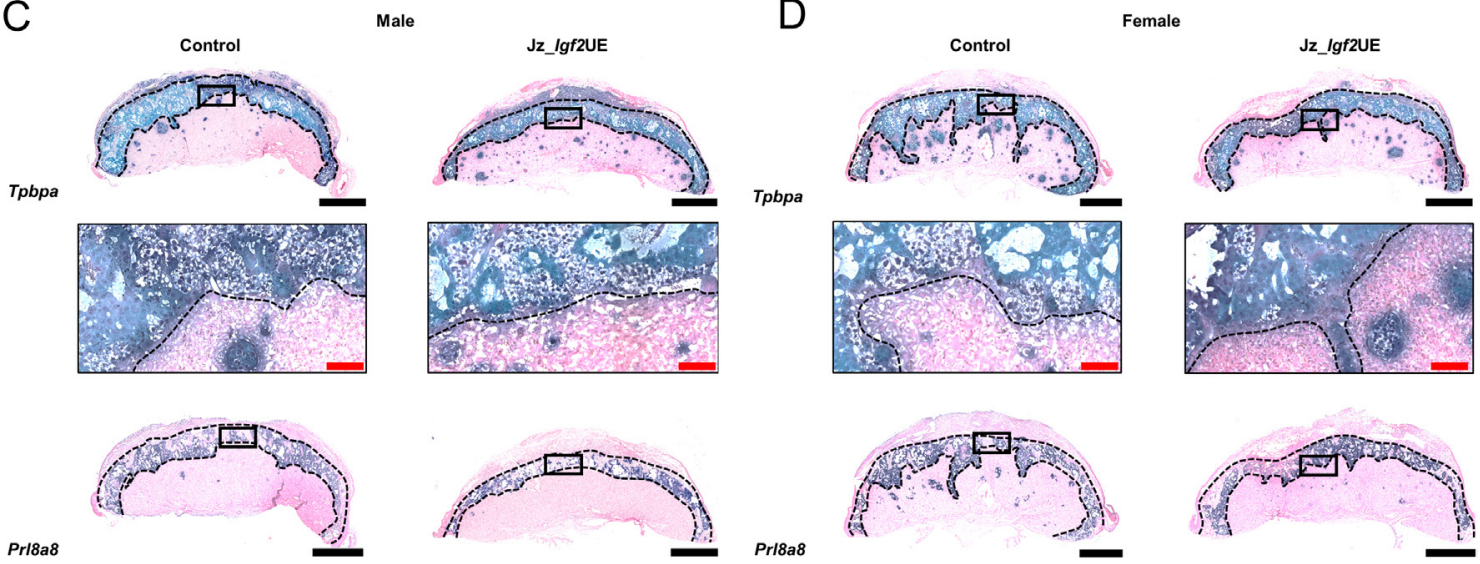

Prl8a8
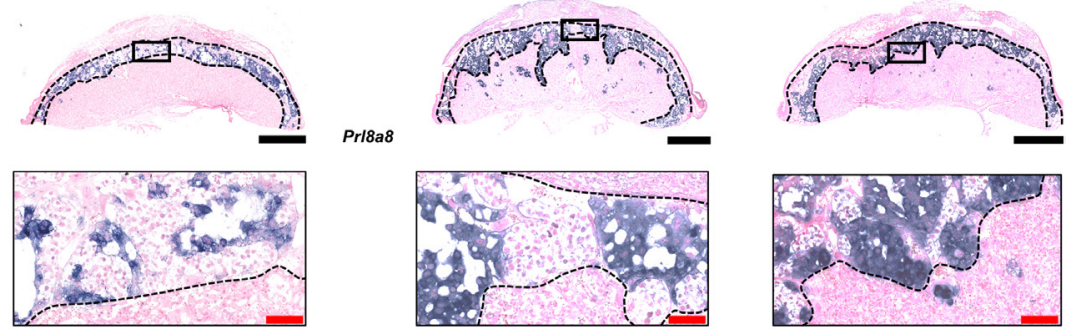

Figure 3

Expression and localisation of endocrine cell markers at D16. (A and B) Expression of endocrine cell markers relative to housekeeping geometric mean of Hprt and Ywhaz using qPCR in (A) males (control $n=10$ and UE $n=8$ ) and (B) females (control $n=10$ and UE $n=12$; except for Gjb3 where UE $n=11$ and

Hand1 UE $n=10$ ), across 8 litters. Values presented as mean + S.E.M. with significance assessed by $t$-test. (C and D) In situ hybridization of Tpbpa and Pr/8a8 in mouse placentas in (C) males and (D) females. Black boxes represent the area magnified in the image. Black bar represents $1 \mathrm{~mm}$. Red bar represents $100 \mu \mathrm{m}$.

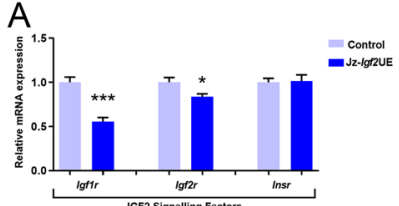

C

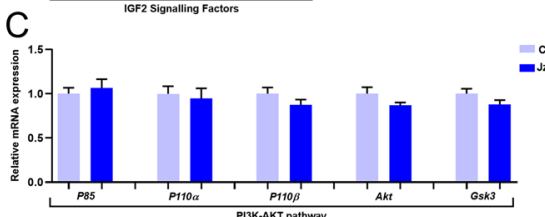

E

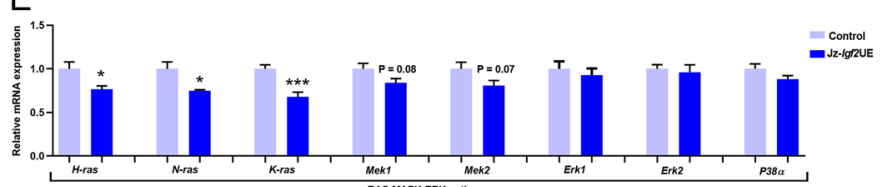

F

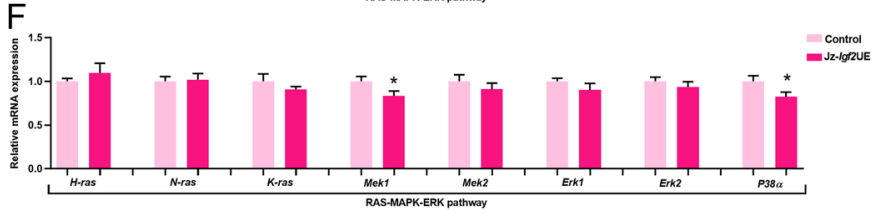

D
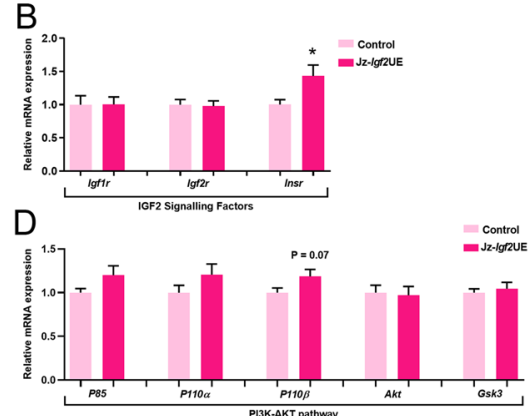

Figure 4

Jz-Igf2UE alters the expression of IGF2 signaling factors but not downstream members of the PI3K-AKT pathway. Expression of (A and B) IGF2 signaling factors, (C and D) PI3K-AKT pathway genes and ( $E$ and F) RAS-MAPK-ERK pathway genes relative to housekeeping geometric mean of Hprt and Ywhaz with Jz-lgf2UE using qPCR in (A, $\mathrm{C}$ and $\mathrm{E}$ ) males (control $n=10$ and UE $n=8$ ) and (B, D and F) females (control $n=10$ and UE $n=12$; except for $\mathrm{H}$-ras where control $n=9$ ), across 8 litters. Values presented as mean + S.E.M. with significance assessed by $t$-test $(P<0.05=*$, $P<0.001=* * *)$. 

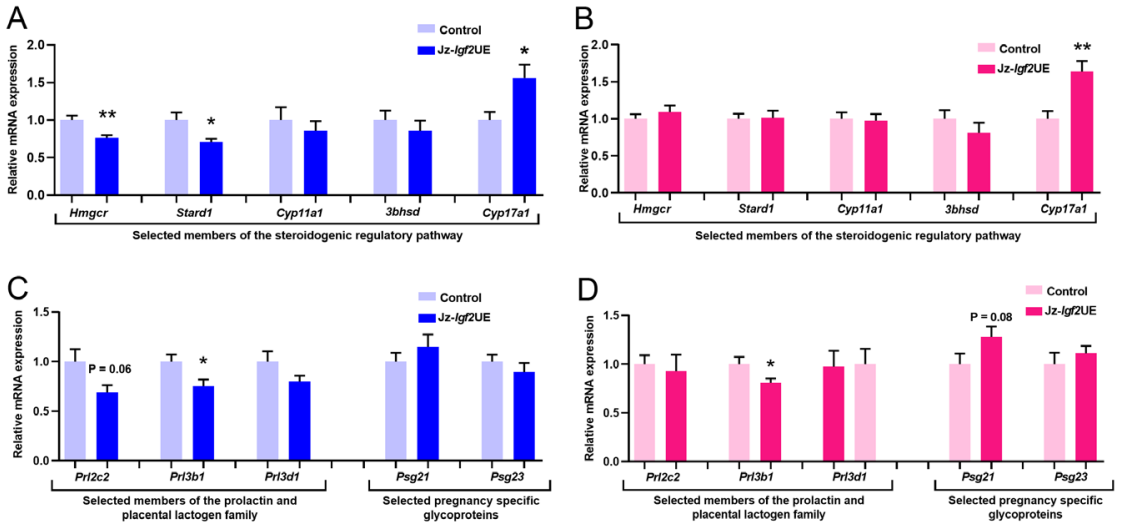

Figure 5

Jz-Igf2UE alters the expression of Jz hormones and steroidogenic pathway genes. Expression of (A and $B$ ) steroidogenic pathway regulatory genes and ( $C$ and D) selected mouse Prl and Psg genes relative to housekeeping geometric mean of Hprt and Ywhaz with Jz-Igf2UE using qPCR in (A and C) males (control $n=10$ and UE $n=8$; except for Cypt17a1 where control $n=9$ ) and (B and D) females (control $n=10$ and UE $n=12$; except for Cyp11a1 and Cyp17a1 control $n=9$ and Stard1, Cyp11a1, 3bhsd, Prl3b1 and Prl3d1 UE $n=11$ ), across 8 litters. Values presented as mean + S.E.M. with significance assessed by $t$-test $(P<0.05=*$, $P<0.01=* *)$.
Jz-Igf2UE in males or females (Fig. 5). Thus, Jz-Igf2UE affects the expression of hormone-related genes by the placental Jz in a manner that partly depends on sex of the fetus.

\section{Discussion}

To date, our understanding of the role of IGF2 in the mouse placenta has been limited to global or Lz specific manipulations of $I g f 2$. In this study, we generated a novel model of Jz-specific loss of Igf2 to examine its significance in regulating mouse placental endocrine function. The specificity of the knockout was validated using in situ hybridisation and qPCR analysis of Igf2 expression. In the current study, we found that Jz-Igf2UE compromised the formation of SpT and GC in the placental Jz and the capacity for steroid and placental lactogen hormone production. These changes were related to alterations in the expression of receptors and signaling pathways that are responsive to IGF2 and depended on the sex of the fetus. Taken together, these data show that Jz-derived Igf2 regulates placental endocrine capacity in the mouse in a manner that is determined, in part, by fetal sex.

Global loss of $I g f 2$ in mice led to feto-placental growth restriction during the last two-thirds of gestation (Baker et al. 1993, DeChiara et al. 1990, 1991). Moreover, deletion of the Lz specific Igf2PO transcript also led to feto-placental growth restriction (Constância et al. 2002). However, in this study, Jz-Igf2UE had no significant effect on fetal or placental weights compared to controls. This suggests that $\mathrm{Jz} I g f 2$ is not directly responsible for regulating fetal or placental growth up until day 16 of pregnancy in a litter with fetuses of different genotypes. Indeed, Lz Igf2 may be more essential for placental growth up to this stage of pregnancy, as the Igf $2 P O$ knockout placentas displayed the same degree of growth restriction as global Igf2 knockouts until day 14 (Constância et al. 2005). To minimise possible effects of variations in the maternal environment on fetoplacental phenotype due to Jz-Igf2UE, data in this study were collected from litters of mixed genotype. However, the presence of a mutant placenta that has perturbed functional capacity can influence the phenotype of geneticallywild-type littermates (Tunster et al. 2016a, López-Tello et al. 2019). Thus, there could be changes in the feto-placental phenotype of both the control and Jz-Igf2UE that we were unable to identify due to the shared gestational environment. Future work should compare feto-placental phenotype between litters that are entirelywild-type and entirely Jz-Igf2UE mutant.

While there was no reduction in placental weight, Jz volume was significantly reduced by Jz-Igf2UE for female fetuses. This was partly due to decreased Jz GC and Jz SpT volumes and was associated with qualitatively less $\mathrm{Jz}$ interdigitation in females, but not in males with Jz-Igf2UE compared to control. We do not know the biological significance of altered Jz interdigitation in Igf2UE female fetuses. However, previous studies have shown that the integrity of the Jz/Lz boundary is susceptible to genetic manipulation (Tunster et al. 2010, 2016b, Naruse et al. 2014, Hasan et al. 2015, Camm et al. 2018), our data would now suggest this may occur in a manner dependent on fetal sex. Nonetheless, the reduced GC volume found in Igf2UE female fetuses correlates with previous research showing that constitutive loss of Igf2 leads to an $80 \%$ reduction in the number of glycogen containing cells in the placenta (Lopez et al. 1996). However, the GC volume reduction seen in the female Jz-Igf2UE placentas is less severe (16\%). Deletion of Igf2PO (Lz specific IGF2) also results in reduced placental GC at a higher level than observed with Jz-Igf2UE (Sferruzzi-Perri et al. 2011b). This suggests that IGF2 from the Lz may be more important in the formation or maintenance of GC in the Jz. Alternatively, as GC normally decline in abundance from D16.5 to term 
(Coan et al. 2006), the reduced Jz GC volume in females could be due to an early activation or accelerated loss of GC with Jz-Igf2UE.

Despite previous work showing that IGF2 can exert an anti-apoptotic function (Sferruzzi-Perri et al. 2017), we found no difference in the levels of the apoptotic marker, caspase-3 in the placental Jz in response to Jz-Igf2UE. The decrease in Jz GC volume but lack of a change in Jz apoptosis, GC size or glycogen content in female placentas suggests that Jz-Igf2UE leads to fewer GCs with normal glycogen storage capacity compared to the control female placentas. This finding differs from previous work in ubiquitous null mice showing that $I g f 2$ increases the activity of the glycogen synthesis pathway in the placenta (Lopez et al. 1996) and other tissues, like the liver (Lopez et al. 1999, Liang et al. 2010). The PI3KAKT pathway promotes glucose uptake and glycogen synthesis downstream of ligands like IGF2 (Forbes et al. 2008, Huang et al. 2018) and disrupted PI3K-AKT signaling leads to reduced glycogen accumulation in the placenta of mice (Dong et al. 2012, Sferruzzi-Perri et al. 2016). In females, but not males, Jz-Igf2UE significantly increased the expression of Insr in the placental Jz. There was also a trend for increased $p 110 \beta$, suggesting enhanced capacity for PI3K-AKT signaling in females and not males with Jz-Igf2UE. INSR has almost as high an affinity for IGF2 as its natural ligand, insulin. INSR also has a much lower affinity for IGF1, which instead has the highest affinity for IGF1R (Germain-Lee et al. 1992, Blanquart et al. 2008). Our data suggest that females may respond to Jz Igf2 loss by increasing the ability of IGF2 to bind INSR to stimulate PI3K-AKT signaling pathway activation and maintain placental glycogen synthesis. In males, Jz-Igf2UE significantly decreased $I g f 2 r$ expression and did not affect PI3K-AKT pathway expression in the placental Jz. Unlike IGF1R, IGF2R has no tyrosine kinase activity and primarily acts as a clearance receptor by targeting IGF2 for lysosomal degradation (Frago et al. 2016). Therefore, our findings indicate that the placenta of males responded to Jz-Igf2UE by decreasing the degradation of IGF2, which, in turn, may have preserved PI3K-AKT signaling and glycogen synthesis. Taking our findings from both sexes together, our data demonstrate that the placenta may compensate for Igf2 loss in the Jz by increasing IGF2 signaling capacity via two different mechanisms, increased sensitivity and increased ligand abundance in female and male fetuses, respectively.

IGF2 signals via the MAPK pathway to promote proliferation (Forbes et al. 2008). Therefore, it is perhaps not surprising that components of the MAPK signaling

(C) 2020 Society for Endocrinology Published by Bioscientifica Ltd. Printed in Great Britain pathway were downregulated by Jz-Igf2UE in both the placental Jz of male and female fetuses. However, while the level of Igf2 loss was comparable in both fetal sexes, the expression of specific components in the MAPK signaling pathway in the placental Jz differed between females and males. In males, early components of the MAPK pathway, $H$-ras, $N$-ras and $K$-ras, were significantly reduced and there were trends for a decrease seen with Mek1 and Mek2, which are further down the pathway, in response to Jz-Igf2UE. In contrast, in females, only Mek1 and $P 38 \alpha$ expression were decreased by Jz-Igf2UE. The greater reduction in MAPK signaling in males with Jz-Igf2UE is consistent with the diminished $I g f 1 r$ expression seen in male fetuses, but not females; as IGF1R activates the RAS-MAPK-ERK (Forbes et al. 2008). However, the formation of the $\mathrm{Jz}$ and its constituent volume of GCs were compromised by Jz-Igf2UE in female and not male fetuses. There are also sexually disparate differences in IGF1R expression and MAPK signaling activity in the rodent placenta in response to maternal manipulations including exercise, dexamethasone treatment, inhalation hypoxia and alcohol intake (Cuffe et al. 2011, 2014, Gårdebjer et al. 2014, Briffa et al. 2017, Mangwiro et al. 2018). Maternal alcohol consumption in rats and dexamethasone treatment in mice also disrupts the formation of the Jz and GC in placenta specifically of female fetuses (Cuffe et al. 2011, Gårdebjer et al. 2014).

In the current study, disparities in the placenta Jz phenotype with Jz-Igf2UE between the fetal sexes are likely related to the specific components of the MAPK pathway that are altered. For instance Mek1 and particularly $P 38 \alpha$ loss in mice are associated with defects in Jz formation in mice (Giroux et al. 1999, Mudgett et al. 2000, Li et al. 2003, Abell et al. 2009). In the present study, Igf1r expression by the Jz was unaltered by Jz-Igf2UE in female fetuses. Igf $2 r$ was also unchanged and Insr adaptively increased by Jz-Igf2UE in females. Previous work has shown that loss of the Insr and Igf1r in mice does not affect placental development, including the formation of the Jz or GCs (Esquiliano et al. 2009). Collectively our data and that of others support the notion for the existence of an unknown receptor that mediates the effects of IGF2 on placental formation $\left(\mathrm{XR}_{\mathrm{p}}\right)$ (Baker et al. 1993, Esquiliano et al. 2009). However, our data additionally suggests that $\mathrm{XR}_{\mathrm{p}}$ may function or is differentially responsive to challenges, like reduced $I g f 2$ availability in the placenta of males and females. INSR and IGF1R hybrids and INSR isoforms have been reported to be expressed by the human placenta (Soos et al. 1993). Future work should explore the contribution of these 
hybrid receptors to IGF2-mediated effects in the placenta, including the $\mathrm{Jz}$ in mice.

The expression of $P r l 3 b 1$ was reduced and expression of Cyp17a1 was increased in males and females by Jz-Igf2UE. Prl3b1, which encodes placental lactogen 2 (PL2), is expressed by SpT and several TGC lineages (Simmons et al. 2008). Previous work has also shown a positive correlation of Prl3b1 and Igf2 expression/ signaling by the placenta in rodents (Ain et al. 2005, Ishida et al. 2007, Sferruzzi-Perri et al. 2016, Napso et al. 2019). PL2 maintains production of progesterone by the corpus luteum in culture (Thordarson et al. 1997) and stimulates production of insulin by neonatal mouse cultured pancreatic islets (Brelje et al. 1993). Cyp17a1 encodes a key steroidogenic enzyme that promotes the production of estrogens (Miller 2002). Estrogen is important for increasing maternal insulin sensitivity and maintaining glucose homeostasis during pregnancy (Brănişteanu \& Mathieu 2003). IGF2 has been shown to increase Cyp17a1 expression in human adult (L'Allemand et al. 1996) and fetal adrenocortical cells (Mesiano \& Jaffe 1993) and stimulates estrogen production in bovine granulosa cells (Spicer \& Aad 2007). Together, this suggests that IGF2 may exert tissue-specific effects on estrogen production or that the upregulated placental Jz Cyp17a1 expression may be a secondary effect of the Jz-Igf2UE. In the placentas of male fetuses, Jz-Igf2UE also trended to reduce the expression of $\operatorname{Pr} 2 \mathrm{2c} 2$, which encodes proliferin, and significantly decreased the expression of additional steroidogenic pathway genes, $\mathrm{Hmgcr}$ and Stard1. Earlier work has demonstrated that IGF2 and activation of the RAS-MAPK-ERK pathway increased Stard1 expression and steroidogenesis in adrenocortical and prostate cancer cells (Gyles et al. 2001, Lubik et al. 2013). The greater impact on steroidogenic gene expression in the placental Jz by $\mathrm{Jz}-I g f 2 \mathrm{UE}$ in males may therefore be related to the observed diminished expression of early components of the RASMAPK-ERK pathway. Regardless of the mechanisms involved, future work is required to determine whether physiological adaptations in the mother may be hindered due to altered placental steroidogenesis and Prl3b1 expression when she is carrying litters containing Jz-Igf2UE mutants.

This study has illustrated that the resultant placental endocrine phenotype exhibited by males and females differs in response to Jz-Igf2UE. However, the mechanisms underlying the sexually discrepant findings are largely unknown. In murine development, sexually dimorphic alterations in epigenetic regulation have been observed as early as the eight-cell stage (Lowe et al. 2015).
Additionally, while the paternal $\mathrm{X}$ chromosome is selectively inactivated in mice, numerous placental genes can escape this, including Slc38a5, which encodes an amino acid transporter (Finn et al. 2014). Therefore, increased dosage of X-inactivation escaping genes in females may contribute to sex-specific differences. Conversely, the Y chromosome contains novel coding genes (Gubbay et al. 1990, Yamauchi et al. 2014), which may influence placenta function and account for the observed sexual dimorphism. Furthermore, hormone production by the fetal gonads or adrenal gland, which are active from D10-13.5 and vary between male and females (Kalisch-Smith et al. 2017), may also aid in the sexually distinct changes in placental phenotype observed.

Other studies have also shown sexually dimorphic responses to a pregnancy insult (Clifton 2010). For instance, there was a greater alteration in placental gene expression in females vs males in response to maternal dietary perturbations in mice (Mao et al. 2010). There are also variations in the number and types of genes involved in specific functions like nutrient metabolism in response to a maternal high-fat diet in the placenta of female and male fetuses (Gabory et al. 2012). Females, but not males, also displayed a reduction in placental mass and Jz weight in response to maternal dexamethasone treatment in mice (Cuffe et al. 2011). Female rodents also more readily displayed adaptations in placental morphology and gene expression in response to maternal hypoxia (Cuffe et al. 2014) and advanced age (Napso et al. 2019). Overall, the reason why a greater phenotypic response to Jz-Igf2UE is observed in female placentas remains unclear. However, it is clear that this is not a unique phenomenon and that sexually dimorphic responses in the placenta need to continue to be addressed in the future.

It is important to note that the expression of placental hormones and signaling pathway genes in the current study was assessed only at the RNA level, with no assessment of protein levels or activity. While future work should prioritise measuring the levels of proteins, including the phosphorylation status of those within the PI3K-AKT and MAPK pathways in the placenta (SferruzziPerri et al. 2011b, Higgins et al. 2016), currently there are no reliable protein assays to assess individual murine PRL or PSG subtypes in the placenta or maternal circulation. Moreover, as pregnant dams used in the current study carried litters of mixed genotype, the effect of Jz-Igf2UE on placental hormone output and, hence, maternal circulating abundance will be diluted by the contribution of hormones coming from the control placentas she is also carrying. Subject to the availability of commercially 
reliable assays, maternal serum hormone concentrations could be assessed by generating litters comprised entirely of one genotype in future work. Alternatively, the secretome of individual placentas from Jz-Igf2UE mixed genotype litters could be explored in vitro.

In conclusion, Jz-Igf2UE alters the cellular composition and hormone expression of the Jz in the mouse placenta. However, the nature of these changes was dependent on fetal sex. Despite changes in placental endocrine phenotype with Jz-Igf2UE, there was no impact on fetal or placental weight in a litter of mixed genotype at day 16. Future studies are required to determine whether altered placental endocrine phenotype may be associated with changes in maternal physiology and in the postnatal health of the offspring. Additionally, it is yet to be determined what impact Jz-specific Igf2 overexpression has on the endocrine phenotype of the mouse placenta. Our findings may be important in the context of human pregnancy, as dysregulated expression of $I g f 2$, its signaling pathway and placental hormones have been reported in human placentas in women with abnormal fetal growth and gestational diabetes (Laviola et al. 2005, Le et al. 2013, Su et al. 2016, Liao et al. 2017, Ngala et al. 2017).

\section{Supplementary materials}

This is linked to the online version of the paper at https://doi.org/10.1530/ JOE-20-0128.

\section{Declaration of interest}

The authors declare that there is no conflict of interest that could be perceived as prejudicing the impartiality of the research reported.

\section{Funding}

This work was supported by a Royal Society Dorothy Hodgkin Research Fellowship, Academy of Medical of Sciences Springboard Grant and MRC New Investigator grant to ANSP (grant numbers DH130036/RG74249, SBF002/1028/RG88501 and MR/R022690/1/RG93186, respectively). BRLA received stipendiary support from the Cambridge Trust and Wolfson College. SJT was funded by a Next Generation Fellowship from the Centre for Trophoblast Research and an Early Career Grant from the Society for Endocrinology.

\section{Data availability}

The datasets generated and analysed during the current study are not publicly available but are available from the corresponding author on reasonable request.

\section{Acknowledgements}

The authors thank Miguel Constância and lonel Sandovici for providing the TpbpaCre and Igf2Flox animals used in this study and Ionel Sandovici for editorial feedback. The authors also thank the Combined Animal Facility for their assistance in animal husbandry. Finally, the authors thank Abigail Fowden for allowing the study to be undertaken under her Home Office project license.

\section{References}

Abell AN, Granger DA, Johnson NL, Vincent-Jordan N, Dibble CF \& Johnson GL 2009 Trophoblast stem cell maintenance by fibroblast growth factor 4 requires MEKK4 activation of Jun N-terminal kinase. Molecular and Cellular Biology 29 2748-2761. (https://doi.org/10.1128/ MCB.01391-08)

Ain R, Canham LN \& Soares MJ 2005 Dexamethasone-induced intrauterine growth restriction impacts the placental prolactin family, insulin-like growth factor-II and the Akt signaling pathway. Journal of Endocrinology 185 253-263. (https://doi.org/10.1677/joe.1.06039)

Baker J, Liu JP, Robertson EJ \& Efstratiadis A 1993 Role of insulin-like growth factors in embryonic and postnatal growth. Cell 75 73-82. (https://doi.org/10.1016/S0092-8674(05)80085-6)

Barbour LA, Shao J, Qiao L, Pulawa LK, Jensen DR, Bartke A, Garrity M, Draznin B \& Friedman JE 2002 Human placental growth hormone causes severe insulin resistance in transgenic mice. American Journal of Obstetrics and Gynecology 186 512-517. (https://doi.org/10.1067/ mob.2002.121256)

Barbour LA, Shao J, Qiao L, Leitner W, Anderson M, Friedman JE \& Draznin B 2004 Human placental growth hormone increases expression of the p85 regulatory unit of phosphatidylinositol 3-kinase and triggers severe insulin resistance in skeletal muscle. Endocrinology 145 1144-1150. (https://doi.org/10.1210/en.2003-1297)

Barke TL, Money KM, Du L, Serezani A, Gannon M, Mirnics K \& Aronoff DM 2019 Sex modifies placental gene expression in response to metabolic and inflammatory stress. Placenta 78 1-9. (https://doi. org/10.1016/j.placenta.2019.02.008)

Blanquart C, Achi J \& Issad T 2008 Characterization of IRA/IRB hybrid IRs using bioluminescence resonance energy transfer. Biochemistry and Pharmacology 76 873-883. (https://doi.org/10.1016/j.bcp.2008.07.027)

Blois SM, Tirado-González I, Wu J, Barrientos G, Johnson B, Warren J, Freitag N, Klapp BF, Irmak S, Ergun S, et al. 2012 Early expression of pregnancy-specific glycoprotein 22 (PSG22) by trophoblast cells modulates angiogenesis in mice. Biology of Reproduction 86191. (https://doi.org/10.1095/biolreprod.111.098251)

Brănişteanu DD \& Mathieu C 2003 Progesterone in gestational diabetes mellitus: guilty or not guilty? Trends in Endocrinology and Metabolism 14 54-56. (https://doi.org/10.1016/s1043-2760(03)00003-1)

Brelje TC, Scharp DW, Lacy PE, Ogren L, Talamantes F, Robertson M, Friesen HG \& Sorenson RL 1993 Effect of homologous placental lactogens, prolactins, and growth hormones on islet B-cell division and insulin secretion in rat, mouse, and human islets: implication for placental lactogen regulation of islet function during pregnancy. Endocrinology 132 879-887. (https://doi.org/10.1210/ endo.132.2.8425500)

Brelje TC, Stout LE, Bhagroo NV \& Sorenson RL 2004 Distinctive roles for prolactin and growth hormone in the activation of signal transducer and activator of transcription 5 in pancreatic islets of langerhans. Endocrinology 145 4162-4175. (https://doi.org/10.1210/en.2004-0201)

Brice AL, Cheetham JE, Bolton VN, Hill NC \& Schofield PN 1989 Temporal changes in the expression of the insulin-like growth factor II gene associated with tissue maturation in the human fetus. Development 106 543-554. https://joe.bioscientifica.com https://doi.org/10.1530/JOE-20-0128 (c) 2020 Society for Endocrinology Published by Bioscientifica Ltd. Printed in Great Britain 
Briffa JF, Hosseini SS, Tran M, Moritz KM, Cuffe JSM \& Wlodek ME 2017 Maternal growth restriction and stress exposure in rats differentially alters expression of components of the placental glucocorticoid barrier and nutrient transporters. Placenta 59 30-38. (https://doi. org/10.1016/j.placenta.2017.09.006)

Burton GJ, Fowden AL \& Thornburg KL 2016 Placental origins of chronic disease. Physiological Reviews 96 1509-1565. (https://doi.org/10.1152/ physrev.00029.2015)

Camm EJ, Botting KJ \& Sferruzzi-Perri AN 2018 Near to one's heart: the intimate relationship between the placenta and fetal heart. Frontiers in Physiology 9 629. (https://doi.org/10.3389/fphys.2018.00629)

Carter AM 2012 Evolution of placental function in mammals: the molecular basis of gas and nutrient transfer, hormone secretion, and immune responses. Physiological Reviews 92 1543-1576. (https://doi. org/10.1152/physrev.00040.2011)

Chellakooty M, Vangsgaard K, Larsen T, Scheike T, Falck-Larsen J, Legarth J, Andersson AM, Main KM, Skakkebaek NE \& Juul A 2004 A longitudinal study of intrauterine growth and the placental growth hormone (GH)insulin-like growth factor I axis in maternal circulation: association between placental GH and fetal growth. Journal of Clinical Endocrinology and Metabolism 89 384-391. (https://doi.org/10.1210/jc.2003-030282)

Chen H, Li Y, Shi J \& Song W 2016 Role and mechanism of insulin-like growth factor 2 on the proliferation of human trophoblasts in vitro. Journal of Obstetrics and Gynaecology Research 42 44-51. (https://doi. org/10.1111/jog.12853)

Clifton VL 2010 Review: Sex and the human placenta: mediating differential strategies of fetal growth and survival. Placenta 31 (Supplement) S33-S39. (https://doi.org/10.1016/j. placenta.2009.11.010)

Coan PM, Ferguson-Smith AC \& Burton GJ 2004 Developmental dynamics of the definitive mouse placenta assessed by stereology. Biology of Reproduction 70 1806-1813. (https://doi.org/10.1095/ biolreprod.103.024166)

Coan PM, Conroy N, Burton GJ \& Ferguson-Smith AC 2006 Origin and characteristics of glycogen cells in the developing murine placenta. Developmental Dynamics 235 3280-3294. (https://doi.org/10.1002/ dvdy.20981)

Constância M, Hemberger M, Hughes J, Dean W, Ferguson-Smith A Fundele R, Stewart F, Kelsey G, Fowden A, Sibley C, et al. 2002 Placental-specific IGF-II is a major modulator of placental and fetal growth. Nature 417 945-948. (https://doi.org/10.1038/nature00819)

Constância M, Angiolini E, Sandovici I, Smith P, Smith R, Kelsey G, Dean W, Ferguson-Smith A, Sibley CP, Reik W, et al. 2005 Adaptation of nutrient supply to fetal demand in the mouse involves interaction between the Igf2 gene and placental transporter systems. PNAS 102 19219-19224. (https://doi.org/10.1073/pnas.0504468103)

Cox B, Kotlyar M, Evangelou AI, Ignatchenko V, Ignatchenko A Whiteley K, Jurisica I, Adamson SL, Rossant J \& Kislinger T 2009 Comparative systems biology of human and mouse as a tool to guide the modeling of human placental pathology. Molecular Systems Biology 5 279. (https://doi.org/10.1038/msb.2009.37)

Cox B, Sharma P, Evangelou AI, Whiteley K, Ignatchenko V, Ignatchenko A, Baczyk D, Czikk M, Kingdom J, Rossant J, et al. 2011 Translational analysis of mouse and human placental protein and mRNA reveals distinct molecular pathologies in human preeclampsia Molecular and Cellular Proteomics 10 M111.012526. (https://doi. org/10.1074/mcp.M111.012526)

Cuffe JSM, Dickinson H, Simmons DG \& Moritz KM 2011 Sex specific changes in placental growth and MAPK following short term maternal dexamethasone exposure in the mouse. Placenta 32 981-989. (https://doi.org/10.1016/j.placenta.2011.09.009)

Cuffe JS, Walton SL, Singh RR, Spiers JG, Bielefeldt-Ohmann H, Wilkinson L, Little MH \& Moritz KM 2014 Mid-to late term hypoxia in the mouse alters placental morphology, glucocorticoid regulatory pathways and nutrient transporters in a sex-specific manner.
Journal of Physiology 592 3127-3141. (https://doi.org/10.1113/ jphysiol.2014.272856)

Curchoe C, Zhang S, Bin Y, Zhang X, Yang L, Feng D, O’Neill M \& Tian XC 2005 Promoter-specific expression of the imprinted IGF2 gene in cattle (Bos taurus). Biology of Reproduction 73 1275-1281. (https://doi.org/10.1095/biolreprod.105.044727)

Dearden L \& Ockleford C 1983 Structure of human trophoblasts: correlation with function. In Biology of Trophoblast. Eds YW Loke \& A Whyte. New York, NY, USA: Elsevier, pp. 69-110.

DeChiara TM, Efstratiadis A \& Robertsen EJ 1990 A growth-deficiency phenotype in heterozygous mice carrying an insulin-like growth factor II gene disrupted by targeting. Nature 345 78-80. (https://doi. org/10.1038/345078a0)

DeChiara TM, Robertson EJ \& Efstratiadis A 1991 Parental imprinting of the mouse insulin-like growth factor II gene. Cell 64 849-859. (https://doi.org/10.1016/0092-8674(91)90513-x)

Demetriou C, Abu-Amero S, Thomas AC, Ishida M, Aggarwal R, Al-Olabi L, Leon LJ, Stafford JL, Syngelaki A, Peebles D, et al. 2014 Paternally expressed, imprinted insulin-like growth factor-2 in chorionic villi correlates significantly with birth weight. PLOS ONE 9 e85454. (https://doi.org/10.1371/journal.pone.0085454)

Desforges M \& Sibley CP 2009 Placental nutrient supply and fetal growth. International Journal of Developmental Biology 18 377-390. (https://doi. org/10.1387/ijdb.082765md)

Dimasuay KG, Boeuf P, Powell TL \& Jansson T 2016 Placental responses to changes in the maternal environment determine fetal growth. Frontiers in Physiology 7 12. (https://doi.org/10.3389/ fphys.2016.00012)

Dong Y, Zhang L, Zhang S, Bai Y, Chen H, Sun X, Yong W, Li W, Colvin SC, Rhodes SJ, et al. 2012 Phosphatase of regenerating liver 2 (PRL2) is essential for placental development by down-regulating PTEN (phosphatase and tensin homologue deleted on chromosome 10) and activating Akt protein. Journal of Biological Chemistry 287 32172-32179. (https://doi.org/10.1074/jbc.M112.393462)

Esquiliano DR, Guo W, Liang L, Dikkes P \& Lopez MF 2009 Placental glycogen stores are increased in mice with $\mathrm{H} 19$ null mutations but not in those with insulin or IGF type 1 receptor mutations. Placenta 30 693-699. (https://doi.org/10.1016/j.placenta.2009.05.004)

Finn EH, Smith CL, Rodriguez J, Sidow A \& Baker JC 2014 Maternal bias and escape from $\mathrm{X}$ chromosome imprinting in the midgestation mouse placenta. Developmental Biology 390 80-92. (https://doi. org/10.1016/j.ydbio.2014.02.020)

Forbes K, Westwood M, Baker PN \& Aplin JD 2008 Insulin-like growth factor I and II regulate the life cycle of trophoblast in the developing human placenta. American Journal of Physiology: Cell Physiology 294 C1313-C1322. (https://doi.org/10.1152/ajpcell.00035.2008)

Fowden AL, Giussani DA \& Forhead AJ 2006 Intrauterine programming of physiological systems: causes and consequences. Physiology 21 29-37. (https://doi.org/10.1152/physiol.00050.2005)

Frago S, Nicholls RD, Strickland M, Hughes J, Williams C, Garner L, Surakhy M, Maclean R, Rezgui D, Prince SN, et al. 2016 Functional evolution of IGF2: IGF2R domain 11 binding generates novel structural interactions and a specific IGF2 antagonist. PNAS 113 E2766-E2775. (https://doi.org/10.1073/pnas.1513023113)

Gabory A, Ferry L, Fajardy I, Jouneau L, Gothié JD, Vigé A, Fleur C, Mayeur S, Gallou-Kabani C, Gross MS, et al. 2012 Maternal diets trigger sex-specific divergent trajectories of gene expression and epigenetic systems in mouse placenta. PLoS ONE 7 e47986. (https:// doi.org/10.1371/journal.pone.0047986)

Gaccioli F \& Lager S 2016 Placental nutrient transport and intrauterine growth restriction. Frontiers in Physiology 7 40. (https://doi. org/10.3389/fphys.2016.00040)

Gårdebjer EM, Cuffe JSM, Pantaleon M, Wlodek ME \& Moritz KM 2014 Periconceptional alcohol consumption causes fetal growth restriction and increases glycogen accumulation in the late https://joe.bioscientifica.com

https://doi.org/10.1530/JOE-20-0128 (c) 2020 Society for Endocrinology Published by Bioscientifica Ltd. Printed in Great Britain 
gestation rat placenta. Placenta 35 50-57. (https://doi.org/10.1016/j. placenta.2013.10.008)

Georgiades P, Ferguson-Smith AC \& Burton GJ 2002 Comparative developmental anatomy of the murine and human definitive placentae. Placenta 23 3-19. (https://doi.org/10.1053/ plac.2001.0738)

Germain-Lee EL, Janicot M, Lammers R, Ullrich A \& Casella SJ 1992 Expression of a type I insulin-like growth factor receptor with low affinity for insulin-like growth factor II. Biochemical Journal $\mathbf{2 8 1}$ 413-417. (https://doi.org/10.1042/bj2810413)

Giroux S, Tremblay M, Bernard D, Cardin-Girard JF, Aubry S, Larouche L, Rousseau S, Huot J, Landry J, Jeannotte L, et al. 1999 Embryonic death of Mek1-deficient mice reveals a role for this kinase in angiogenesis in the labyrinthine region of the placenta. Current Biology 9 369-372. (https://doi.org/10.1016/s0960-9822(99)80164-x)

Gluckman PD, Hanson MA, Cooper C \& Thornburg KL 2008 Effect of in utero and early-life conditions on adult health and disease. New England Journal of Medicine 359 61-73. (https://doi.org/10.1056/ NEJMra0708473)

Gubbay J, Collignon J, Koopman P, Capel B, Economou A, Münsterberg A, Vivian N, Goodfellow P \& Lovell-Badge R 1990 A gene mapping to the sex-determining region of the mouse $\mathrm{Y}$ chromosome is a member of a novel family of embryonically expressed genes. Nature 346 245-250. (https://doi.org/10.1038/346245a0)

Guvakova MA 2007 Insulin-like growth factors control cell migration in health and disease. International Journal of Biochemistry and Cell Biology 39 890-909. (https://doi.org/10.1016/j.biocel.2006.10.013)

Gyles SL, Burns CJ, Whitehouse BJ, Sugden D, Marsh PJ, Persaud SJ \& Jones PM 2001 ERKs regulate cyclic AMP-induced steroid synthesis through transcription of the steroidogenic acute regulatory (StAR) gene. Journal of Biological Chemistry 276 34888-34895. (https://doi. org/10.1074/jbc.M102063200)

Haley VL, Barnes DJ, Sandovici I, Constancia M, Graham CF, Pezzella F, Bühnemann C, Carter EJ \& Hassan AB 2012 Igf2 pathway dependency of the Trp53 developmental and tumour phenotypes. EMBO Molecular Medicine 4 705-718. (https://doi.org/10.1002/emmm.201101105)

Han VK, Bassett NI, Walton JO \& Challis JR 1996 The expression of insulin-like growth factor (IGF) and IGF-binding protein (IGFBP) genes in the human placenta and membranes: evidence for IGFIGFBP interactions at the feto-maternal interface. Journal of Clinical Endocrinology and Metabolism 81 2680-2693. (https://doi.org/10.1210/ jcem.81.7.8675597)

Hasan MZ, Ikawati M, Tocharus J, Kawaichi M \& Oka C 2015 Abnormal development of placenta in HtrA1-deficient mice. Developmental Biology 397 89-102. (https://doi.org/10.1016/j. ydbio.2014.10.015)

Higgins JS, Vaughan OR, de Liger EF, Fowden AL \& Sferruzzi-Perri AN 2016 Placental phenotype and resource allocation to fetal growth are modified by the timing and degree of hypoxia during mouse pregnancy. Journal of Physiology 594 1341-1356. (https://doi. org/10.1113/JP271057)

Huang X, Liu G, Guo J \& Su Z 2018 The PI3K/AKT pathway in obesity and type 2 diabetes. International Journal of Biological Sciences $\mathbf{1 4}$ 1483-1496. (https://doi.org/10.7150/ijbs.27173)

Ishida M, Ohashi S, Kizaki Y, Naito JI, Horiguchi K \& Harigaya T 2007 Expression profiling of mouse placental lactogen II and its correlative genes using a cDNA microarray analysis in the developmental mouse placenta. Journal of Reproduction and Development 53 69-76. (https:// doi.org/10.1262/jrd.18002)

Jarrett 2nd JC, Ballejo G, Saleem TH, Tsibris JC \& Spellacy WN 1984 The effect of prolactin and relaxin on insulin binding by adipocytes from pregnant women. American Journal of Obstetrics and Gynecology 149 250-255. (https://doi.org/10.1016/0002-9378(84)90223-0)

Jones JI \& Clemmons DR 1995 Insulin-like growth factors and their binding proteins: biological actions. Endocrine Reviews 16 3-34. (https://doi.org/10.1210/edrv-16-1-3)
Kalisch-Smith JI, Simmons DG, Dickinson H \& Moritz KM 2017 Review: Sexual dimorphism in the formation, function and adaptation of the placenta. Placenta 54 10-16. (https://doi.org/10.1016/j. placenta.2016.12.008)

Kent LN, Ohboshi S \& Soares MJ 2012 Akt1 and insulin-like growth factor 2 (Igf2) regulate placentation and fetal/postnatal development. International Journal of Developmental Biology 56 255-261. (https://doi. org/10.1387/ijdb.113407lk)

Koutsaki M, Sifakis S, Zaravinos A, Koutroulakis D, Koukoura O \& Spandidos DA 2011 Decreased placental expression of hPGH, IGF-I and IGFBP-1 in pregnancies complicated by fetal growth restriction. Growth Hormone and IGF Research 21 31-36. (https://doi. org/10.1016/j.ghir.2010.12.002)

L'Allemand DA, Penhoat AR, Lebrethon MC, Ardevol R, Baehr V, Oelkers W \& Saez JM 1996 Insulin-like growth factors enhance steroidogenic enzyme and corticotropin receptor messenger ribonucleic acid levels and corticotropin steroidogenic responsiveness in cultured human adrenocortical cells. Journal of Clinical Endocrinology and Metabolism 81 3892-3897. (https://doi.org/10.1210/ jcem.81.11.8923834)

Laviola L, Perrini S, Belsanti G, Natalicchio A, Montrone C, Leonardini A, Vimercati A, Scioscia M, Selvaggi L, Giorgino R, et al. 2005 Intrauterine growth restriction in humans is associated with abnormalities in placental insulin-like growth factor signaling. Endocrinology 146 1498-1505. (https://doi.org/10.1210/en.2004-1332)

LaVoie HA \& King SR 2009 Transcriptional regulation of steroidogenic genes: STARD1, CYP11A1 and HSD3B. Experimental Biology and Medicine 234 880-907. (https://doi.org/10.3181/0903-MR-97)

Le TN, Elsea SH, Romero R, Chaiworapongsa T \& Francis GL 2013 Prolactin receptor gene polymorphisms are associated with gestational diabetes. Genetic Testing and Molecular Biomarkers 17 567-571. (https://doi.org/10.1089/gtmb.2013.0009)

Lescisin KR, Varmuza S \& Rossant J 1988 Isolation and characterization of a novel trophoblast-specific cDNA in the mouse. Genes and Development 2 1639-1646. (https://doi.org/10.1101/gad.2.12a.1639)

Leturque A, Burnol AF, Ferre P \& Girard J 1984 Pregnancy-induced insulin resistance in the rat: assessment by glucose clamp technique. American Journal of Physiology 246 E25-E31. (https://doi.org/10.1152/ ajpendo.1984.246.1.E25)

Li HY, Chang SP, Yuan CC, Chao HT, Ng HT \& Sung YJ 2003 Induction of p38 mitogen-activated protein kinase-mediated apoptosis is involved in outgrowth of trophoblast cells on endometrial epithelial cells in a model of human trophoblast-endometrial interactions. Biology of Reproduction 69 1515-1524. (https://doi.org/10.1095/ biolreprod.103.015669)

Liang L, Guo WH, Esquiliano DR, Asai M, Rodriguez S, Giraud J, Kushner JA, White MF \& Lopez MF 2010 Insulin-like growth factor 2 and the insulin receptor, but not insulin, regulate fetal hepatic glycogen synthesis. Endocrinology 151 741-747. (https://doi. org/10.1210/en.2009-0705)

Liao S, Vickers MH, Taylor RS, Fraser M, McCowan LME, Baker PN \& Perry JK 2017 Maternal serum placental growth hormone, insulin-like growth factors and their binding proteins at 20 weeks' gestation in pregnancies complicated by gestational diabetes mellitus. Hormones 16 282-290. (https://doi.org/10.14310/horm.2002.1747)

Lopez MF, Dikkes P, Zurakowski DA \& Villa-Komaroff L 1996 Insulinlike growth factor II affects the appearance and glycogen content of glycogen cells in the murine placenta. Endocrinology 137 2100-2108. (https://doi.org/10.1210/endo.137.5.8612553)

Lopez MF, Dikkes P, Zurakowski D, Villa-Komaroff L \& Majzoub JA 1999 Regulation of hepatic glycogen in the insulin-like growth factor II-deficient mouse. Endocrinology 140 1442-1448. (https://doi. org/10.1210/endo.140.3.6602)

López-Tello J, Pérez-García V, Khaira J, Kusinski LC, Cooper WN, Andreani A, Grant I, Fernández DLE, Lam BY, Hemberger M, et al. 2019 Fetal and trophoblast PI3K p110 $\alpha$ have distinct roles in https://joe.bioscientifica.com

https://doi.org/10.1530/JOE-20-0128 (c) 2020 Society for Endocrinology Published by Bioscientifica Ltd. Printed in Great Britain 
regulating resource supply to the growing fetus in mice. eLife $\mathbf{8}$ e45282. (https://doi.org/10.7554/eLife.45282.001)

Lowe R, Gemma C, Rakyan VK \& Holland ML 2015 Sexually dimorphic gene expression emerges with embryonic genome activation and is dynamic throughout development. BMC Genomics 16 295. (https:// doi.org/10.1186/s12864-015-1506-4)

Lubik AA, Gunter JH, Hollier BG, Ettinger S, Fazli L, Stylianou N, Hendy SC, Adomat HH, Gleave ME, Pollak M, et al. 2013 IGF2 increases de novo steroidogenesis in prostate cancer cells. EndocrineRelated Cancer 20 173-186. (https://doi.org/10.1530/ERC-12-0250)

Mangwiro YTM, Cuffe JSM, Briffa JF, Mahizir D, Anevska K, Jefferies AJ, Hosseini S, Romano T, Moritz KM \& Wlodek ME 2018 Maternal exercise in rats upregulates the placental insulin-like growth factor system with diet- and sex-specific responses: minimal effects in mothers born growth restricted. Journal of Physiology 596 5947-5964. (https://doi.org/10.1113/JP275758)

Mao J, Zhang X, Sieli PT, Falduto MT, Torres KE \& Rosenfeld CS 2010 Contrasting effects of different maternal diets on sexually dimorphic gene expression in the murine placenta. PNAS 107 5557-5562. (https://doi.org/10.1073/pnas.1000440107)

McClain DA 1991 Different ligand affinities of the two human insulin receptor splice variants are reflected in parallel changes in sensitivity for insulin action. Molecular Endocrinology 5 734-739. (https://doi. org/10.1210/mend-5-5-734)

McIntyre HD, Serek R, Crane DI, Veveris-Lowe T, Parry A, Johnson S, Leung KC, Ho KK, Bougoussa M, Hennen G, et al. 2000 Placental growth hormone $(\mathrm{GH})$, GH-binding protein, and insulin-like growth factor axis in normal, growth-retarded, and diabetic pregnancies: correlations with fetal growth. Journal of Clinical Endocrinology and Metabolism 85 1143-1150. (https://doi.org/10.1210/jcem.85.3.6480)

McLellan AS, Fischer B, Dveksler G, Hori T, Wynne F, Ball M, Okumura K Moore T \& Zimmermann W 2005 Structure and evolution of the mouse pregnancy-specific glycoprotein (Psg) gene locus. BMC Genomics 6 4. (https://doi.org/10.1186/1471-2164-6-4)

Mesiano S \& Jaffe RB 1993 Interaction of insulin-like growth factor-II and estradiol directs steroidogenesis in the human fetal adrenal toward dehydroepiandrosterone sulfate production. Journal of Clinical Endocrinology and Metabolism 77 754-758. (https://doi.org/10.1210/ jcem.77.3.8396578)

Miller WL 2002 Androgen biosynthesis from cholesterol to DHEA. Molecular and Cellular Endocrinology 198 7-14. (https://doi. org/10.1016/s0303-7207(02)00363-5)

Mirlesse V, Frankenne F, Alsat E, Poncelet M, Hennen G \& EvainBrion D 1993 Placental growth hormone levels in normal pregnancy and in pregnancies with intrauterine growth retardation. Pediatric Research 34 439-442. (https://doi.org/10.1203/00006450199310000-00011)

Mudgett JS, Ding J, Guh-Siesel L, Chartrain NA, Yang L, Gopal S \& Shen MM 2000 Essential role for p38 $\alpha$ mitogen-activated protein kinase in placental angiogenesis. PNAS 97 10454-10459. (https://doi. org/10.1073/pnas.180316397)

Musial B, Fernandez-Twinn DS, Vaughan OR, Ozanne SE, Voshol P, Sferruzzi-Perri AN \& Fowden AL 2016 Proximity to delivery alters insulin sensitivity and glucose metabolism in pregnant mice. Diabetes 65 851-860. (https://doi.org/10.2337/db15-1531)

Napso T, Yong HEJ, Lopez-Tello J \& Sferruzzi-Perri AN 2018 The role of placental hormones in mediating maternal adaptations to support pregnancy and lactation. Frontiers in Physiology 9 1091. (https://doi. $\operatorname{org} / 10.3389 /$ fphys.2018.01091)

Napso T, Hung YP, Davidge ST, Care AS \& Sferruzzi-Perri AN 2019 Advanced maternal age compromises fetal growth and induces sexspecific changes in placental phenotype in rats. Scientific Reports 91. (https://doi.org/10.1038/s41598-019-53199-x)

Naruse M, Ono R, Irie M, Nakamura K, Furuse T, Hino T, Oda K, Kashimura M, Yamada I, Wakana S, et al. 2014 Sirh7/Ldoc1 knockout mice exhibit placental P4 overproduction and delayed parturition. Development 141 4763-4771. (https://doi.org/10.1242/ dev.114520)

Ngala RA, Fondjo LA, Gmagna P, Ghartey FN \& Awe MA 2017 Placental peptides metabolism and maternal factors as predictors of risk of gestational diabetes in pregnant women. A case-control study. PLoS ONE 12 e0181613. (https://doi.org/10.1371/journal.pone.0181613)

Nogues N, Del Rio JA, Perez-Riba M, Soriano E, Flavell RA \& Boronat A 1997 Placenta-specific expression of the rat growth hormone-releasing hormone gene promoter in transgenic mice. Endocrinology 138 3222-3227. (https://doi.org/10.1210/endo.138.8.5295)

Oka Y, Rozek LM \& Czech MP 1985 Direct demonstration of rapid insulin-like growth factor II receptor internalization and recycling in rat adipocytes. Insulin stimulates 125I-insulin-like growth factor II degradation by modulating the IGF-II receptor recycling process. Journal of Biological Chemistry $2609435-9442$.

Õunap K 2016 Silver-Russell syndrome and Beckwith-Wiedemann syndrome: opposite phenotypes with heterogeneous molecular etiology. Molecular Syndromology 7 110-121. (https://doi. org/10.1159/000447413)

Plows JF, Stanley JL, Baker PN, Reynolds CM \& Vickers MH 2018 The pathophysiology of gestational diabetes mellitus. International Journal of Molecular Sciences 19 3342. (https://doi.org/10.3390/ ijms19113342)

Rakoczy J, Padmanabhan N, Krzak AM, Kieckbusch J, Cindrova-Davies T \& Watson ED 2017 Dynamic expression of TET1, TET2, and TET3 dioxygenases in mouse and human placentas throughout gestation. Placenta 59 46-56. (https://doi.org/10.1016/j.placenta.2017.09.008)

Redline RW, Chernicky CL, Tan HQ, Ilan J \& Ilan J 1993 Differential expression of insulin-like growth factor-II in specific regions of the late (post day 9.5) murine placenta. Molecular Reproduction and Development 36 121-129. (https://doi.org/10.1002/mrd.1080360202)

Rosenfeld CS 2015 Sex-specific placental responses in fetal development. Endocrinology 156 3422-3434. (https://doi.org/10.1210/en.2015-1227)

Sferruzzi-Perri AN 2018 Regulating needs: Exploring the role of insulinlike growth factor-2 signalling in materno-fetal resource allocation. Placenta 64 16-22. (https://doi.org/10.1016/j.placenta.2018.01.005)

Sferruzzi-Perri AN \& Camm EJ 2016 The programming power of the placenta. Frontiers in Physiology 7 33. (https://doi.org/10.3389/ fphys.2016.00033)

Sferruzzi-Perri AN, Macpherson AM, Roberts CT \& Robertson SA 2009 Csf2 null mutation alters placental gene expression and trophoblast glycogen cell and giant cell abundance in mice. Biology of Reproduction 81 207-221. (https://doi.org/10.1095/biolreprod.108.073312)

Sferruzzi-Perri AN, Owens JA, Pringle KG \& Roberts CT 2011 $a$ The neglected role of insulin-like growth factors in the maternal circulation regulating fetal growth. Journal of Physiology 589 7-20. (https://doi.org/10.1113/jphysiol.2010.198622)

Sferruzzi-Perri AN, Vaughan OR, Coan PM, Suciu MC, Darbyshire R, Constancia M, Burton GJ \& Fowden AL $2011 b$ Placental-specific Igf2 deficiency alters developmental adaptations to undernutrition in mice. Endocrinology 152 3202-3212. (https://doi.org/10.1210/en.20110240)

Sferruzzi-Perri AN, Vaughan OR, Forhead AJ \& Fowden AL $2013 a$ Hormonal and nutritional drivers of intrauterine growth. Current Opinion in Clinical Nutrition and Metabolic Care 16 298-309. (https:// doi.org/10.1097/MCO.0b013e32835e3643)

Sferruzzi-Perri AN, Vaughan OR, Haro M, Cooper WN, Musial B, Charalambous M, Pestana D, Ayyar S, Ferguson-Smith AC, Burton GJ, et al. $2013 \mathrm{~b}$ An obesogenic diet during mouse pregnancy modifies maternal nutrient partitioning and the fetal growth trajectory. FASEB Journal 27 3928-3937. (https://doi.org/10.1096/fj.13-234823)

Sferruzzi-Perri AN, López-Tello J, Fowden AL \& Constancia M 2016 Maternal and fetal genomes interplay through phosphoinositol 3-kinase (PI3K)-p110 $\alpha$ signaling to modify placental resource allocation. PNAS 113 11255-11260. (https://doi.org/10.1073/ pnas.1602012113) 
Sferruzzi-Perri AN, Sandovici I, Constancia M \& Fowden AL 2017 Placental phenotype and the insulin-like growth factors: resource allocation to fetal growth. Journal of Physiology 595 5057-5093. (https://doi.org/10.1113/JP273330)

Sferruzzi-Perri AN, López-Tello J, Napso T \& Yong HE 2020 Exploring the causes and consequences of maternal metabolic maladaptations during pregnancy: lessons from animal models. Placenta [epub]. (https://doi.org/10.1016/j.placenta.2020.01.015)

Simmons DG \& Cross JC 2005 Determinants of trophoblast lineage and cell subtype specification in the mouse placenta. Developmental Biology 284 12-24. (https://doi.org/10.1016/j.ydbio.2005.05.010)

Simmons DG, Fortier AL \& Cross JC 2007 Diverse subtypes and developmental origins of trophoblast giant cells in the mouse placenta. Developmental Biology 304 567-578. (https://doi. org/10.1016/j.ydbio.2007.01.009)

Simmons DG, Rawn SM, Davies A, Hughes M \& Cross JC 2008 Spatial and temporal expression of the 23 murine prolactin/placental lactogenrelated genes is not associated with their position in the locus. $B M C$ Genomics 9 352. (https://doi.org/10.1186/1471-2164-9-352)

Snyder SK, Wessner DH, Wessells JL, Waterhouse RM, Wahl LM, Zimmermann W \& Dveksler GS 2001 Pregnancy-specific glycoproteins function as immunomodulators by inducing secretion of IL-10, IL-6 and TGF-beta1 by human monocytes. American Journal of Reproductive Immunology 45 205-216. (https://doi.org/10.1111/ j.8755-8920.2001.450403.x)

Soares MJ 2004 The prolactin and growth hormone families: pregnancy-specific hormones/cytokines at the maternal-fetal interface. Reproductive Biology and Endocrinology 2 51. (https://doi. org/10.1186/1477-7827-2-51)

Soos MA, Field CE \& Siddle K 1993 Purified hybrid insulin/insulin-like growth factor-I receptors bind insulin-like growth factor-I, but not insulin, with high affinity. Biochemical Journal 290 419-426. (https:// doi.org/10.1042/bj2900419)

Spicer LJ \& Aad PY 2007 Insulin-like growth factor (IGF) 2 stimulates steroidogenesis and mitosis of bovine granulosa cells through the IGF1 receptor: role of follicle-stimulating hormone and IGF2 receptor. Biology of Reproduction 77 18-27. (https://doi.org/10.1095/ biolreprod.106.058230)

Stojanov T, Alechna S \& O'Neill C 1999 In-vitro fertilization and culture of mouse embryos in vitro significantly retards the onset of insulin-like growth factor-II expression from the zygotic genome. Molecular Human Reproduction 5 116-124. (https://doi.org/10.1093/ molehr/5.2.116)

Su R, Wang C, Feng H, Lin L, Liu X, Wei Y \& Yang H 2016 Alteration in expression and methylation of IGF2/H19 in placenta and umbilical cord blood are associated with macrosomia exposed to intrauterine hyperglycemia. PLoS ONE 11 e0148399. (https://doi.org/10.1371/ journal.pone.0148399)

Sutter-Dub MT \& Dazey B 1979 Role of progesterone in the insulinresistance during pregnancy in the rat (author's transl). Annales d'Endocrinologie 40 37-38.
Takeda K, Toda K, Saibara T, Nakagawa M, Saika K, Onishi T, Sugiura T \& Shizuta Y 2003 Progressive development of insulin resistance phenotype in male mice with complete aromatase (CYP19) deficiency. Journal of Endocrinology 176 237-246. (https://doi.org/10.1677/ joe.0.1760237)

Thomsen BM, Clausen HV, Larsen LG, Nürnberg L, Ottesen B \& Thomsen HK 1997 Patterns in expression of insulin-like growth factor-II and of proliferative activity in the normal human first and third trimester placenta demonstrated by non-isotopic in situ hybridization and immunohistochemical staining for MIB-1. Placenta 18 145-154. (https://doi.org/10.1016/s0143-4004(97)90086-2)

Thordarson G, Galosy S, Gudmundsson GO, Newcomer B, Sridaran R \& Talamantes F 1997 Interaction of mouse placental lactogens and androgens in regulating progesterone release in cultured mouse luteal cells. Endocrinology 138 3236-3241. (https://doi.org/10.1210/ endo.138.8.5309)

Tunster SJ, Tycko B \& John RM 2010 The imprinted Phlda2 gene regulates extraembryonic energy stores. Molecular and Cellular Biology 30 295-306. (https://doi.org/10.1128/MCB.00662-09)

Tunster SJ, Creeth HDJ \& John RM $2016 a$ The imprinted Phlda2 gene modulates a major endocrine compartment of the placenta to regulate placental demands for maternal resources. Developmental Biology 409 251-260. (https://doi.org/10.1016/j.ydbio.2015.10.015)

Tunster SJ, McNamara GI, Creeth HDJ \& John RM $2016 b$ Increased dosage of the imprinted Ascl2 gene restrains two key endocrine lineages of the mouse placenta. Developmental Biology 418 55-65. (https://doi. org/10.1016/j.ydbio.2016.08.014)

Vasavada RC, Garcia-Ocaña A, Zawalich WS, Sorenson RL, Dann P, Syed M, Ogren L, Talamantes F \& Stewart AF 2000 Targeted expression of placental lactogen in the beta cells of transgenic mice results in beta cell proliferation, islet mass augmentation, and hypoglycemia. Journal of Biological Chemistry 275 15399-15406. (https://doi. org/10.1074/jbc.275.20.15399)

Wada T, Hori S, Sugiyama M, Fujisawa E, Nakano T, Tsuneki H, Nagira K, Saito S \& Sasaoka T 2010 Progesterone inhibits glucose uptake by affecting diverse steps of insulin signaling in 3T3-L1 adipocytes. American Journal of Physiology: Endocrinology and Metabolism 298 E881-E888. (https://doi.org/10.1152/ajpendo.00649.2009)

Weinhaus AJ, Stout LE, Bhagroo NV, Brelje TC \& Sorenson RL 2007 Regulation of glucokinase in pancreatic islets by prolactin: a mechanism for increasing glucose-stimulated insulin secretion during pregnancy. Journal of Endocrinology 193 367-381. (https://doi. org/10.1677/JOE-07-0043)

Wislocki GB \& Bennett HS 1943 The histology and cytology of the human and monkey placenta, with special reference to the trophoblast. American Journal of Anatomy 73 335-449. (https://doi. org/10.1002/aja.1000730303)

Yamauchi Y, Riel JM, Stoytcheva Z \& Ward MA 2014 Two Y genes can replace the entire $\mathrm{Y}$ chromosome for assisted reproduction in the mouse. Science 343 69-72. (https://doi.org/10.1126/ science.1242544)

Received in final form 1 May 2020

Accepted 7 May 2020

Accepted Manuscript published online 7 May 2020 https://joe.bioscientifica.com https://doi.org/10.1530/JOE-20-0128
(C) 2020 Society for Endocrinology Published by Bioscientifica Ltd. Printed in Great Britain 